\title{
Antimalarial Drug Resistance and Implications for the WHO Global Technical Strategy
}

\author{
Matthew M. Ippolito ${ }^{1,2,3} \cdot$ Kara A. Moser $^{4}$ • Jean-Bertin Bukasa Kabuya ${ }^{5}$. Clark Cunningham ${ }^{6}$ • Jonathan J. Juliano ${ }^{7,8,9}$
}

Accepted: 1 March 2021 / Published online: 14 March 2021

(C) The Author(s), under exclusive licence to Springer Nature Switzerland AG 2021

\begin{abstract}
Purpose of Review Five years have passed since the World Health Organization released its Global Technical Strategy for Malaria (GTS). In that time, progress against malaria has plateaued. This review focuses on the implications of antimalarial drug resistance for the GTS and how interim progress in parasite genomics and antimalarial pharmacology offer a bulwark against it.

Recent Findings For the first time, drug resistance-conferring genes have been identified and validated before their global expansion in malaria parasite populations. More efficient methods for their detection and elaboration have been developed, although low-density infections and polyclonality remain a nuisance to be solved. Clinical trials of alternative regimens for multidrug-resistant malaria have delivered promising results. New agents continue down the development pipeline, while a nascent infrastructure in sub-Saharan Africa for conducting phase I trials and trials of transmission-blocking agents has come to fruition after years of preparation.

Summary These and other developments can help inform the GTS as the world looks ahead to the next two decades of its implementation. To remain ahead of the threat that drug resistance poses, wider application of genomic-based surveillance and optimization of existing and forthcoming antimalarial drugs are essential.
\end{abstract}

Keywords Malaria $\cdot$ Plasmodium $\cdot$ Drug resistance $\cdot$ World Health Organization Global Technical Strategy for Malaria

\section{Introduction}

Malaria stubbornly persists in tropical and subtropical regions of the world despite concerted global efforts that date back to the World Health Organization (WHO) Global Malaria Eradication Programme in the 1950s and 1960s [1,2]. The program largely excluded sub-Saharan Africa, and its ultimate abandonment was driven by a host of factors including, in part, the emergence and spread of drug resistance to chloroquine $(\mathrm{CQ})$ and related 4-aminoquinolines in use at the time [3]. Over half a century later, the emergence of antimalarial

This article is part of the Topical Collection on Infectious Disease Epidemiology

Jonathan J. Juliano

jonathan_juliano@med.unc.edu

1 Divisions of Clinical Pharmacology and Infectious Diseases, Department of Medicine, Johns Hopkins University School of Medicine, Baltimore, MD, USA

2 The Johns Hopkins Malaria Research Institute, Johns Hopkins University School of Public Health, Baltimore, MD, USA

3 Department of Pharmacology and Molecular Sciences, Johns Hopkins University School of Medicine, Baltimore, MD, USA

4 Institute for Global Health and Infectious Diseases, University of North Carolina, Chapel Hill, NC, USA
Clinical Research Department, Tropical Diseases Research Centre, Ndola, Copperbelt Province, Zambia

6 School of Medicine, University of North Carolina, Chapel Hill, NC, USA

7 Division of Infectious Diseases, Department of Medicine, School of Medicine, University of North Carolina, CB\#7030, 130 Mason Farm Rd, Chapel Hill, NC 27599, USA

8 Curriculum in Genetics and Molecular Biology, School of Medicine, University of North Carolina, Chapel Hill, NC, USA

9 Department of Epidemiology, Gillings School of Global Public Health, University of North Carolina, Chapel Hill, NC, USA 
drug resistance remains an ever-present threat to global malaria control.

In 2016, the WHO reaffirmed its vision of global malaria eradication and provided a technical framework to guide local, national, and regional efforts outlined in the Global Technical Strategy for Malaria 2016-2030 [4]. The strategy centers on universal access to malaria testing and treatment, acceleration toward elimination where feasible, enhanced surveillance, continued research and innovation, and infrastructural and capacity-building investments. Soberly, it acknowledges the imposing challenges to malaria control, manifest in the most recent World Malaria Report that documented stalling and, in certain areas ranging from South America to sub-Saharan Africa, reversing progress [5]. The Global Technical Strategy set a milestone of achieving a $40 \%$ reduction in malaria mortality and case incidence by 2020 and a $90 \%$ reduction by 2030 [4]. The latest data suggests that these first milestones will not be met. In response, the WHO updated its agenda to increase focus on high-burden areas [5, 6]. Meanwhile, the current coronavirus pandemic is anticipated to further harm malaria control prospects $[7 \bullet, 8 \bullet]$.

Human malaria is caused by one of five Plasmodium spp. of which $P$. falciparum and $P$. vivax are the most prevalent. While $P$. vivax has a wider geographic range and a biology that poses unique challenges to eradication, $P$. falciparum is responsible for the vast majority of malaria-attributable deaths and is the predominant species in sub-Saharan Africa, which bears $>90 \%$ of the global malaria burden [5]. The other human-infecting species, including $P$. ovale, $P$. malariae, and the zoonotic $P$. knowlesi, are less prevalent, generally less lethal (with the exception of $P$. knowlesi) and less studied in terms of drug resistance. This review therefore focuses primarily on drug resistance in $P$. falciparum, with additional discussion of $P$. vivax.

Malaria, with few exceptions, is treated with combination therapy (Table 1). Artemisinin-based combination therapies (ACTs) are the current first-line agents for curative treatment [9]. A complete course of ACT is also given in severe malaria following induction with intravenous artesunate [9-11]. They combine short-acting but highly potent artemisinin derivatives with less potent, longer-acting agents. The coformulation of agents with mismatched pharmacokinetics, while not unique to antimalarial therapy, is expected to impede the development of artemisinin resistance but comes with the potential expense of promoting resistance to the partner agents which linger for weeks to months at subtherapeutic concentrations [12]. Pharmacologic autoinduction of artemisinins, whereby the compounds upregulate their own metabolism with repeated dosing, may also help promote resistance by exposing parasites to subtherapeutic concentrations over the treatment course [13].

Among threats to malaria control, the emergence and spread of drug-resistant parasites require a response that leverages innovations in parasite genomics, drug development, and multinational collaborations to identify, track, contain, and treat multidrug-resistant malaria (Table 2) [14, 15]. Here, we review and discuss the historical origins and spread of drug-resistant malaria and their impacts on past control efforts, a brief overview of mechanisms of resistance, methods of drug resistance surveillance, the effects of resistance on treatment and prevention, and how innovations in parasite genomics and drug development can advance the Global Technical Strategy.

\section{Historical Origins and Present Distribution of Drug-Resistant Malaria}

Malaria parasite resistance to essentially all currently and previously available antimalarial drugs has arisen multiple times throughout the course of the last century and more. Quinine was the first commercial antimalarial, extracted from the bark of the South American cinchona tree and first traded in Europe in the seventeenth century. By the turn of the twentieth century, quininization, the mass administration of quinine or its relatives, was carried out in large tea estates, sugar and rubber plantations, and similar settings where malaria-naïve workers migrated to malarious areas [16-18]. Early reports of suspected quinine resistance emerged as early as 1910 [19]. Quinine and its relatives were then commonly combined with the early 8-aminoquinolines, forebears to primaquine and tafenoquine, but combination therapy was replaced by $\mathrm{CQ}$ monotherapy with the drug's advent during World War II.

In the middle of the WHO Global Malaria Eradication Programme (1955-1969), the first reports of CQ-resistant P. falciparum emerged independently in South America and Southeast Asia [20, 21]. Within two decades, CQ-resistant $P$. falciparum swept across the tropical and subtropical world [22]. CQ was gradually replaced by sulfadoxinepyrimethamine (SP), but resistance to SP appeared rapidly after its introduction [23-25]. The emergence of drugresistant $P$. falciparum in sub-Saharan Africa was devastating, with doubling to tripling of case incidence and mortality (Fig. 1) [30]. As alternative agents were introduced-proguanil, amodiaquine, mefloquine, piperaquine, atovaquone - the identification of drug-resistant parasites followed closely [31]. Malaria resurged worldwide, and the measurable progress that had been made against malaria during the eradication effort was eroded, compounded by delays in replacing CQ and SP on national formularies with ACTs [32].

After ACTs were introduced in the late 1990s and early 2000s, initial reports of partial artemisinin and ACT resistance appeared in Southeast Asia [33, 34] and were followed by frank treatment failures of artesunate-mefloquine (AS-MQ) and later dihydroartemisinin-piperaquine (DHA-PPQ) due to phenotype- and genotype-confirmed resistance to both the 
Table 1 P. falciparum blood schizonticides currently in use and their associated genetic markers of resistance

\begin{tabular}{|c|c|c|c|c|c|}
\hline \multirow{2}{*}{$\begin{array}{l}\text { Drug class and } \\
\text { agent }\end{array}$} & \multirow[t]{2}{*}{ Available coformulations } & \multicolumn{2}{|c|}{ Timeline of resistance } & \multicolumn{2}{|c|}{ Molecular markers of resistance } \\
\hline & & $\begin{array}{l}\text { Introduction of } \\
\text { agent }\end{array}$ & $\begin{array}{l}\text { First report of } \\
\text { resistance }\end{array}$ & $\begin{array}{l}\text { Implicated } \\
\text { genes }\end{array}$ & $\begin{array}{l}\text { Polymorphism or } \\
\text { variant }\end{array}$ \\
\hline \multicolumn{6}{|l|}{ 4-Aminoquinolines } \\
\hline \multirow[t]{2}{*}{ Chloroquine } & \multirow[t]{2}{*}{ CQ monotherapy } & \multirow[t]{2}{*}{1945} & \multirow[t]{2}{*}{1957} & pfcrt & SNPs \\
\hline & & & & $p f m d r 1$ & SNPs \\
\hline \multirow[t]{2}{*}{ Amodiaquine } & \multirow[t]{2}{*}{ AS-AQ } & \multirow[t]{2}{*}{1951} & \multirow[t]{2}{*}{1971} & pfcrt & SNPs \\
\hline & & & & pfmdrl & SNPs \\
\hline \multicolumn{6}{|l|}{ Arylamino alcohols } \\
\hline \multirow[t]{2}{*}{ Lumefantrine } & \multirow[t]{2}{*}{ AM-LF } & \multirow[t]{2}{*}{$1992^{\mathrm{c}}$} & \multirow[t]{2}{*}{$-^{\mathrm{a}}$} & $p f c r t^{b}$ & $\mathrm{SNPs}^{b}$ \\
\hline & & & & $p f m d r 1^{b}$ & Copy \# variant ${ }^{b}$ \\
\hline Mefloquine & MQ monotherapy, AS-MQ & 1977 & 1982 & pfmdrl & Copy \# variant \\
\hline \multirow[t]{5}{*}{ Quinine } & \multirow[t]{5}{*}{ QN monotherapy } & \multirow[t]{5}{*}{1632} & \multirow[t]{5}{*}{1910} & pfmdrl & SNPs \\
\hline & & & & pfmdr6 & SNPs \\
\hline & & & & $p f c r t$ & SNPs \\
\hline & & & & pfmrpl & SNPs \\
\hline & & & & pfnhel & SNPs \\
\hline \multicolumn{6}{|l|}{ Mannich base } \\
\hline Pyronaridine & AS-PY & 2014 & $-^{\mathrm{a}}$ & $p f c r t^{b}$ & $\mathrm{SNPs}^{b}$ \\
\hline \multicolumn{6}{|l|}{ Artemisinins } \\
\hline Artemether & AM-LF & $1992^{\mathrm{c}}$ & $-^{\mathrm{a}}$ & pfkl3 & SNPs \\
\hline \multirow[t]{2}{*}{ Artesunate } & \multirow{2}{*}{$\begin{array}{l}\text { AS monotherapy, AS-SP, AS-MQ, } \\
\text { AS-PY }\end{array}$} & \multirow[t]{2}{*}{1978} & $2002^{\mathrm{d}}$ & \multirow[t]{2}{*}{$p f k 13$} & \multirow[t]{2}{*}{ SNPs } \\
\hline & & & $2011^{\mathrm{e}}$ & & \\
\hline Dihydroartemisinin & DHA-PPQ & $1997^{\mathrm{e}}$ & $2010^{\mathrm{f}}$ & $p f k 13$ & SNPs \\
\hline \multicolumn{6}{|l|}{ Bisquinoline } \\
\hline Piperaquine & DHA-PPQ & “ & “ & pfpm2 & Copy \# variant \\
\hline & & & & $p f c r t$ & SNPs \\
\hline Naphthoquinone & & & & & \\
\hline Atovaquone & ATQ-PGL & 1996 & $1997^{\mathrm{g}}$ & $p f c y t b$ & SNPs \\
\hline Antifolates & & & & & \\
\hline Proguanil & ATQ-PGL & 1948 & $1949^{\mathrm{h}}$ & $p f d h f r$ & SNPs \\
\hline Pyrimethamine & SP & 1967 & $1967^{\mathrm{i}}$ & $p f d h f r$ & SNPs \\
\hline Sulfadoxine & $\mathrm{SP}$ & “ & “ & pfdhps & SNPs \\
\hline
\end{tabular}

$A M$ artemether, $A Q$ amodiaquine, $A S$ artesunate, $A T Q$ atovaquone, $C Q$ chloroquine, $D H A$ dihydroartemisinin, $L F$ lumefantrine, $M Q$ mefloquine,

$P$ pyrimethamine, $P G L$ proguanil, $P P Q$ piperaquine, $P Y$ pyronaridine, $Q N$ quinine, $S$ sulfadoxine, $S N P s$ single nucleotide polymorphisms

${ }^{\text {a }}$ No confirmed resistance

${ }^{\mathrm{b}}$ From in vitro studies of experimentally generated resistance, unconfirmed role in field isolates

${ }^{\mathrm{c}}$ Introduction of the combination AM-LF

${ }^{\mathrm{d}}$ Date applies to the combination AS-MQ

${ }^{\mathrm{e}}$ Date applies to the combination AS-SP

${ }^{\mathrm{f}}$ Date applies to the combination DHA-PPQ

${ }^{g}$ Resistance to ATQ alone; resistance to the combination ATQ-PGL was detected in 2002

${ }^{\mathrm{h}}$ Resistance to PGL alone; see note above

${ }^{\mathrm{i}}$ Date applies to the combination SP

artemisinin derivates and partner drugs [35••, 36-44]. Treatment failures well exceeded the threshold of $10 \%$ typical for enacting policy change [41]. Drug efficacy studies of the other ACTs have variably found therapeutic failures $>10 \%$, but these studies were limited by small sample sizes and lack of phenotypic and/or genotypic correlates of resistance 
Table 2 Policy prescriptions for confronting antimalarial drug resistance using parasite genomics and clinical pharmacology

\begin{tabular}{|c|c|c|c|}
\hline & Parasite genomics & Antimalarial drug evaluation & Antimalarial pharmacology \\
\hline Innovation & $\begin{array}{l}\text { Identification and validation of new } \\
\text { molecular markers and mechanisms of } \\
\text { resistance } \\
\text { Solutions for genotyping low parasitemia } \\
\text { infections and polyclonality } \\
\text { Development of low-cost genotyping } \\
\text { assays with genetic resolution for } \\
\text { tracking parasite importation }\end{array}$ & $\begin{array}{l}\text { Establishing methods for continuous } \\
\text { culture of } P \text {. vivax } \\
\text { Development of in vitro models for } \\
\text { evaluating antimalarial efficacy for } \\
\text { non-falciparum species } \\
\text { Development of low-cost and simple } \\
\text { methods for monitoring drug quality }\end{array}$ & $\begin{array}{l}\text { Discovery and development of novel } \\
\text { pharmacophores, classes, and mechanisms of } \\
\text { action } \\
\text { Updated paradigms of parasite clearance and } \\
\text { other pharmaco-dynamic parameters of drug } \\
\text { efficacy }\end{array}$ \\
\hline Optimization & $\begin{array}{l}\text { Streamlining genomic techniques to } \\
\text { enhance accessibility } \\
\text { Expansion of tools for assessing the } \\
\text { genetics of polyclonal infections }\end{array}$ & $\begin{array}{l}\text { Strengthening regional collaborations for } \\
\text { resistance testing and surveillance }\end{array}$ & $\begin{array}{l}\text { Dose optimization in pediatric and pregnant } \\
\text { populations earlier in drug development } \\
\text { Broaden uptake of transmission-blocking } \\
\text { 8-aminoquinolines (e.g., single low-dose } \\
\text { primaquine) } \\
\text { Retailor ACT posology and formulation to } \\
\text { prolong their utility (e.g., 6-day regimens, } \\
\text { sequential ACT, triple ACT) }\end{array}$ \\
\hline Investment & $\begin{array}{l}\text { Expansion of sequencing infrastructure in } \\
\text { sub-Saharan Africa } \\
\text { Training in bioinformatics and data } \\
\text { analysis } \\
\text { Development of data visualization tools } \\
\text { for genomic data for policy makers }\end{array}$ & $\begin{array}{l}\text { Expansion of infrastructure for ex vivo and } \\
\text { in vitro antimalarial resistance testing in } \\
\text { sub-Saharan Africa } \\
\text { Expansion of infrastructure for monitoring } \\
\text { drug quality }\end{array}$ & $\begin{array}{l}\text { Support of phase } 1 \text { and } 2 \text { clinical trials in } \\
\text { endemic or endemic-adjacent areas } \\
\text { Instrumentation and human upskilling for } \\
\text { biochemical analysis } \\
\text { Investment in pharmacovigilance systems in } \\
\text { endemic countries }\end{array}$ \\
\hline
\end{tabular}

$A C T$ artemisinin-based combination therapy

[45-48]. One exception is resistance to artesunatesulfadoxine-pyrimethamine (AS-SP) reported in areas of high preexisting antifolate resistance; antifolate resistance effectively reduces AS-SP to artemisinin monotherapy, which is known to fail in up to $50 \%$ of cases due in part to its rapid elimination and autoinduction with repeated doses [13, 49].

Antimalarial resistance in non-falciparum species has been slower to emerge, thought due to lower parasite numbers in the human host and hence fewer mutation events, and, for $P$. vivax and $P$. ovale, the ability to evade blood schizonticides through forming hypnozoites in the liver. In the late 1980s, CQ resistance in P. vivax was first reported in non-immune Australian travels to Papua New Guinea, and by the early 2000s, CQ resistance was also documented in $P$. malariae [50-52]. Genetic signatures of $P$. vivax worldwide suggest that, today, CQ resistance has expanded globally [53].

Today, the distribution of drug-resistant $P$. falciparum remains variable across the globe, reflecting in part patterns in drug deployment and transmission intensity. Resistance to two of the ACTs, DHA-PPQ and AS-MQ, is well documented in Southeast Asia [33, 40]. Reports of ACT treatment failures in malaria-naïve travelers who contracted $P$. falciparum malaria in sub-Saharan Africa echo the first reports of CQresistant malaria, though none contain definitive confirmation of resistance and at least two of the reports included failures attributable to subtherapeutic dosing rather than drug resistance [54-56, 57•, 58, 59]. Evidence of genotypic and phenotypic correlates of resistance to one or more ACT components is beginning to emerge in sub-Saharan Africa, South Asia, and South America including a recent report from Rwanda where P. falciparum kelch13 (pfk13) R561H, P574L, and C469Y alleles - previously linked to a delayed clearance phenotype [60•]—-were detected [33, 40, 61••, 62•, 63•]. Resistance to the antifolates remains widespread, while reversion of CQresistant parasite populations to the $\mathrm{CQ}$-susceptible wild type followed in the wake of withdrawing CQ from national formularies in eastern and central-southern Africa [64-71].

\section{Mechanisms of Antimalarial Resistance}

At the molecular level, the emergence and propagation of drug-resistant Plasmodium spp. are intrinsically tied to the diverse forms assumed by the parasite and the variety of environments it traverses, from the mosquito midgut and salivary glands to human hepatocytes and erythrocytes [31]. The malaria parasite spends most of its life in a haploid state, only briefly diploid during sexual recombination in mosquitoes [72]. The propagation of drug resistance through a parasite population requires mutant parasites to successfully undergo gametocytogenesis and sporogony, two of the parasite lifecycle bottlenecks. Mutations that hamper these or other vital functions will propagate poorly or not at all, as with atovaquone resistance-conferring mutations in the Plasmodium cytochrome b complex which appear to render the parasite intransmissible [73]. 
Fig. 1 Trends in malaria case incidence, deaths, and case fatality after the introduction and spread of chloroquine-resistant malaria into sub-Saharan Africa. Data are from four historical studies [26•, 27-29]
Malaria case incidence per 10 child-years
Malaria deaths per 100 total deaths
Inpatient pediatric case fatality due to malaria
Malaria deaths per 1,000 children

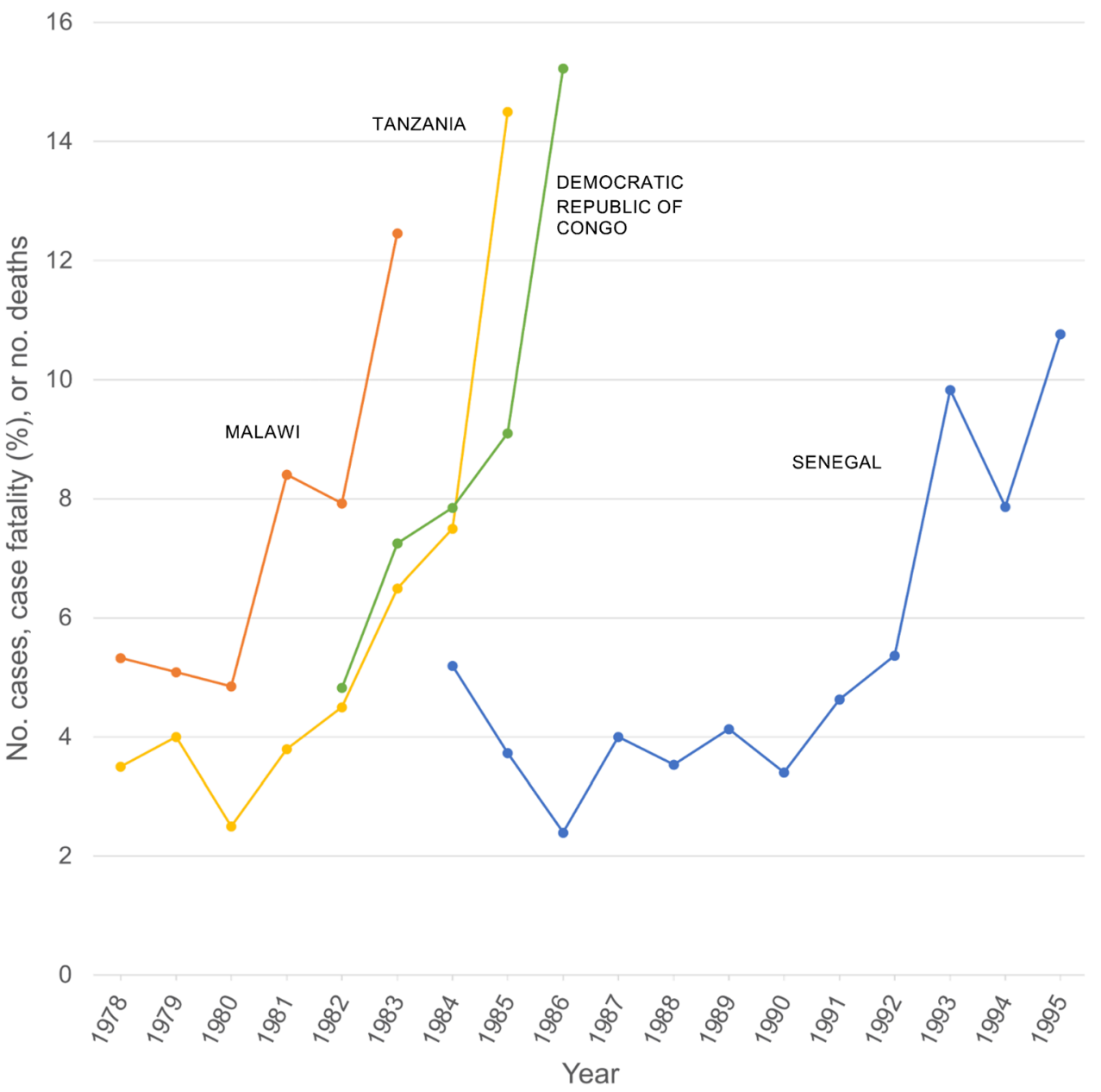

Comprehensive reviews of the mechanisms and genotypic markers of antimalarial drug resistance were recently published elsewhere by Conrad and Ross [74, 75•]. Mechanisms of resistance in malaria parasites include similar mechanisms to those described in other microorganisms (e.g., drug efflux, alteration to the drug target, enzymatic degradation or modification of the drug) as well as less common mechanisms that relate to the parasite's lifecycle and metabolism [76]. For example, mutations in $p f k 13$ mediate susceptibility to artemisinins by prolonging the time the parasite spends in its earlier, less drug-susceptible ring stage and upregulating the unfolded protein response, essentially arresting development while the artemisinin is rapidly eliminated and artemisinindamaged peptides are cleared [77, 78•].

Drug resistance in $P$. vivax and $P$. malariae is less well characterized than in $P$. falciparum. In vivax malaria, relapse from hypnozoites complicates the interpretation of treatment outcomes, further made difficult by the current lack of methods for continuous culture of $P$. vivax [52, 79]. Given these challenges, standardized methods for evaluating the efficacy of antimalarials for $P$. vivax are necessary [80]. Historical comparative studies of quinine and chloroquine for vivax malaria support a definition of treatment failure as any recurrent $P$. vivax parasitemia occurring within a certain window of time after treatment (e.g., treatment failure if within 16 days, likely treatment failure if within 17-28 days, possible treatment failure if after 28 days) [81].

Therapeutic failures of CQ for $P$. vivax infection and candidate drug resistance mutations have been documented in most endemic areas [82-91, 92•], prompting some national programs to adopt ACTs as first line for vivax malaria [80]. There are no firmly established molecular markers of drugresistant $P$. vivax, but population genomic studies of $P$. vivax hint not only at drug pressure from $\mathrm{CQ}$, the first-line $P$. vivax treatment in most countries, but also genetic signatures of possible MQ, antifolate, and artemisinin resistance in areas 
of co-endemic P. falciparum $[53,93]$. There is increasing recognition that mechanisms of drug resistance may differ in substantial ways between different Plasmodium spp. While CQ resistance in P. falciparum is strongly linked to the K76T mutation in the CQ resistance transporter gene ( $p f c r t)$ [94, 95], CQ resistance in $P$. vivax appears to be via an unknown mechanism mediated by transcriptional changes in the orthologous pvcrt-o, suggesting interspecies differences in the native function of the transporter, which still is unknown [96, 97•, 98, 99].

\section{Drug Resistance Surveillance: Clinical, Phenotypic, and Genotypic Detection}

The detection of antimalarial drug resistance relies on clinical, phenotypic, and genotypic data, yet it can be challenging to acquire all three in the resource-deprived settings where malaria is endemic. Current antimalarial resistance surveillance activities therefore often operate using one or two of the three approaches.

Clinical resistance relates to therapeutic failure, wherein a patient experiences persistent or recurrent parasitemia after treatment, and is defined in terms of early or late reappearance of parasites on blood smear and the presence or absence of symptoms [100]. Confirmation of therapeutic failure requires matching the parasite strains from the initial and recurrent episode to distinguish failure from a new infection, which presents sizeable challenges due to multiple-strain (polyclonal) infections, and the often small number of parasites in recurrent episodes [101]. Phenotypic correlates of drug resistance require drug sensitivity testing of in vitro or ex vivo parasite cultures from patients, not currently performed in the course of clinical care nor are the laboratory methods readily available, many of which require specialized assays for individual drugs $[102,103]$. Once specific gene mutations are linked to clinical and phenotypic correlates of drug resistance and validated in field-isolated parasites, genotyping parasites for genetic markers of resistance is a third means of surveillance and the most scalable [104].

In practice, drug resistance surveillance has historically been done through therapeutic efficacy studies (TES) of first-line agents that follow a prespecified WHO protocol, recommended every two years in endemic areas [41]. Today, TES commonly combines clinical outcomes with molecular (genotypic) information [105, 106]. In China and Southeast Asia where containment of already-identified ACT resistance is a high priority, protocols for integrated drug efficacy surveillance that incorporates data from imported as well as local cases are under development [107].

The identification and validation of partial artemisinin resistance-conferring mutations in $p f k 13$ have enabled monitoring for the emergence of artemisinin resistance worldwide
[108]. This is the first time a validated molecular marker of antimalarial drug resistance is available prior to its widespread dissemination. There have now been multiple reports of $p f k 13$ mutations outside of Southeast Asia, though not always accompanied by phenotypic or clinical evidence of drug resistance [61, 109-111]. More recent reports from Guyana, Rwanda, Uganda, and Tanzania have documented validated resistance polymorphisms in pfk $13[61 \bullet \bullet, 63 \bullet, 112-114$, $115 \bullet]$.

\section{Drug Resistance and Malaria Chemotherapy and Chemoprevention}

The WHO Global Technical Strategy calls for universalizing access to malaria chemotherapy and chemoprevention, and revisits an old notion of using chemoprophylaxis in endemic populations, an approach historically reserved for short-term use in malaria-naïve travelers to endemic areas [4]. Expanding the use of antimalarials in such ways should go hand in hand with expanding surveillance for antimalarial drug resistance. The Global Technical Strategy outlines a timeline (every 2 years) and threshold of effectiveness (90\%) for TES of firstline agents [4]. The strategy also emphasizes the need for expanding the genetic library of molecular markers of drug resistance to facilitate early detection. This is particularly relevant in pre-elimination settings where sustained low-level transmission may be more likely to foster resistant parasites, but low malaria incidence precludes antimalarial efficacy studies [116].

As CQ and SP resistance spread, their replacement by ACTs as first-line treatment for uncomplicated malaria contributed to the regained progress against malaria during the first decade and a half of this century [117]. To help preserve ACT efficacy, several alternatives to conventional ACT regimens have been proposed including sequential double combination ACT, prolonged and/or increased daily frequency of ACT dosing, and triple ACT. Recently, clinical trials of triple ACT have demonstrated their safety and efficacy, including in the treatment of multidrug-resistant malaria (NCT03355664 and NCT02453308) [118, 119]. Co-therapy with a second agent to potentiate parasite killing or reverse drug resistance - such as ACTs or CQ with macrolide antibiotics, or CQ with calcium channel blockers - has also been studied but with unpromising results $[120,121]$.

The efficacy and durability of ACTs hinge on several factors. Underdosing of some antimalarial drugs in children and pregnant women is thought to have contributed to drug resistance; thus, pediatric formulations and early dose optimization studies in both children and pregnant women should be counted as a means of forestalling drug resistance and preserving drug efficacy $[122,123]$. The most recent example of this is in PPQ, shown to be suboptimally dosed in the youngest age 
groups, since rectified with newer dosing schedules for DHAPPQ products that nearly double the conventional dose for the smallest children [124]. Other immediately available means of combatting drug resistance are efforts to curtail the circulation of substandard, falsified, and obsolete (e.g., artemisinin or pyrimethamine monotherapy) antimalarial drugs [125-127].

Transmission-blocking interventions are essential to curbing the spread of drug-resistant parasites, some strains of which have shown greater transmissibility than wild-type parasites [128, 129]. Chemotherapeutically, this entails the use of agents with activity against gametocytes, the transmissible stage of the parasite. The only true $P$. falciparum gametocytocides currently available are the 8aminoquinolines, primaquine, and tafenoquine. Different ACTs appear to have differing anti-gametocyte efficacies, but fail to clear gametocytes to the extent of 8 aminoquinolines $[130,131]$. The threat of drug resistance should motivate the global community to more ardently promote wider adoption by national malaria control programs of single low-dose (SLD) primaquine as recommended, in 2012, by the WHO for areas of low transmission and areas of artemisinin resistance [132-134]. This will require further demonstration of SLD primaquine's safety in areas with prevalent glucose-6-phosphate dehydrogenase (G6PD) deficiency, associated with drug-induced hemolytic anemia, as recently done in South Africa, Tanzania, and Central America [135-137], and would benefit from affordable point-of-care tests of G6PD activity.

The WHO endorses three strategies for chemopreventive or presumptive treatment in high-risk groups: intermittent preventive treatment in infants (IPTi), intermittent preventive treatment in pregnancy (IPTp), and seasonal malaria chemoprevention (SMC) [138-140]. IPTi and IPTp are recommended in areas of moderate to high $P$. falciparum transmission, and the IPTi guidelines limit its use to areas where the frequency of the dihydropteroate synthase (dhps) K540E mutation is $\leq 50 \%$ [140]. SMC is recommended in areas of high seasonal transmission and is currently carried out in the Sahel region of Africa [141]. Thirty-nine million children live in areas where SMC is recommended, and modeling suggests that SMC, if widely implemented, could avoid over 21 million malaria cases and 95 thousand deaths annually [142].

Current guidelines for the three preventive strategies propose SP or SP in combination with amodiaquine (AQ) [138-140]. Declines in efficacy have occurred in connection with increasing prevalence of mutations in the antifolate resistance genes dhps and dihydrofolate reductase $(d h f r)[143 \bullet \bullet, 144 \bullet \cdot]$. Alternatives to SP and AQSP have therefore been examined-including ACTs, CQ combined with azithromycin, and others $[145 \bullet, 146,147 \cdot$, 148•, 149-152] — with a particular focus on PPQcontaining regimens given its relatively long half-life, but the readiness with which PPQ resistance may arise warrants caution. All told, IPTi, IPTp, and SMC programs should follow a coherent antimalarial policy that adheres to the principles of anti-infective stewardship and relies on up-to-date drug resistance surveillance data, avoiding first-line agents to minimize drug pressure and thereby helping preserve their efficacy in clinical use.

Lastly, the history of mass drug administration (MDA) for malaria and controversies around its role in malaria control-and in promoting drug resistanceextend back almost 100 years and remain a topic for debate [153]. The bulk of the evidence indicates against its utility except under very constrained circumstances, reflected in current WHO recommendations which limit MDA to complex emergency situations and to areas on the verge of malaria elimination with robust malaria control measures already in place and minimal risk of reimportation [153, 154].

\section{Drug Discovery and Development to Counter Antimalarial Resistance}

Countering antimalarial drug resistance requires new effective therapies. An active antimalarial drug development pipeline has been fostered through private-public partnerships, open-source access to compound libraries, and advances in high-throughput screening that includes the ability to assess stage specificity of candidate compounds $[155,156 \bullet \cdot 157]$. Groundbreaking work in parasite genomics and transcriptomics has accelerated the identification of potential drug targets $[158 \bullet \bullet, 159]$. Antimalarial drug development has also harnessed the latest in clinical pharmacology science, including phase 0 microdose studies, novel nanoformulations of antimalarial compounds, the development of antimalarial biologics, and both in vitro and in silico pharmacometric simulations [160-162]. Updated pharmacodynamic models of parasite clearance and antimalarial activity supplement conventional approaches to how drug efficacy is assessed, helping to inform rational drug development and posology [163-165]. Growing capacity in sub-Saharan Africa for locally conducted phase 1 and 2, studies, which included the first-inhuman study of a novel Plasmodium phosphatidylinositol 4-kinase (PI4K) inhibitor, lends promise that early drug development can increasingly take place in clinically relevant populations $[116,166]$. These efforts have led to a robust pipeline of next-generation and novel classes of antimalarials with activity against artemisinin-resistant Plasmodia that includes the synthetic ozonides, inhibitors of PI4K, and monoclonal antibodies [166-168, 169••, 170-172]. 


\section{Advances in Molecular Surveillance and Bioinformatics}

Molecular surveillance relies on Plasmodium genomics for the identification of drug resistance markers. The use of genome-wide association studies (GWAS) and other population genetic tools to characterize the emergence, mechanisms, and movement of drug-resistant parasites has revolutionized our understanding of the molecular epidemiology of antimalarial resistance with implications for the Global Technical Strategy and national malarial control programs [173].

Next-generation sequencing (NGS) methods, such as targeted amplicon deep sequencing (TADS), are increasingly used to monitor molecular markers of resistance [174-178]. By enabling high-sensitivity, high-throughput analysis of molecular markers, the declining costs and increasing data yield of NGS have positioned it to replace traditional PCR-based methods [179]. Pooled sequencing of individual samples from infected individuals using NGS substantially boosts the number and rate of sample analysis [180-182]. Keeping apace of these innovations in sequencing technology are innovations in bioinformatic methods for the analysis of TADS data [174, 183-185].

At present, several hurdles remain for the widespread implementation of NGS-based methods of molecular surveillance of antimalarial drug resistance. These challenges have recently been reviewed by Ishengoma et al. [186]. The requirement for advanced infrastructure and training amplifies these challenges in the resource-deprived settings where malaria is endemic.

\section{Translational Genomics for Malaria Control}

Like in other areas of antimicrobial drug resistance research, GWAS has become an essential tool for the identification of genetic regions and loci related to antimalarial resistance. Recently reviewed elsewhere by Volkman et al. [187], GWAS has been used to confirm previously suspected drug resistance polymorphisms and identify mechanisms of resistance to new classes of antimalarials [109, 188-195]. Because the emergence of resistance leaves specific signatures in the parasite genome, GWAS and other population linkage approaches can provide clues to how antimalarial resistance emerges and spreads [196-202]. This provides practicable knowledge that can inform surveillance for, anticipatory strategies against, and containment of drug resistance.

For example, with the identification of polymorphisms in $p f k 13$, population linkage studies provided evidence that the mutations associated with artemisinin resistance emerged independently multiple times throughout the Greater Mekong Subregion of Southeast Asia, alerting programs to the fact that containment alone will be insufficient [193]. Subsequent studies showed that successful artemisinin-resistant lineages spread across the region outcompeting other parasites [203-205]. Genomic data can be translated into actionable information for malaria control through use of different visualization tools such as landscape genetics. For artemisinin resistance in the Greater Mekong Subregion, the use of estimated effective migration surfaces has been proposed to demarcate barriers and corridors for parasite migration [206, 207•]. These kinds of approaches have the potential to identify key locations at national and regional levels where interventions should be prioritized for halting the spread of resistance.

While genomic-based approaches have predominantly been used in areas of low transmission where infections tend to be monoclonal, advances in bioinformatics have allowed for similar studies to be undertaken in high-transmission regions in sub-Saharan Africa where infections with multiple strains are common. New deconvolution methods for genomic data allow for more robust interpretations of genomes in polyclonal samples [208, 209]. These early methods have already been used to trace parasite migration between Tanzania and the Zanzibar archipelago [210]. Another approach has leveraged molecular inversion probes to describe long-range migration of parasites and temporal changes in antimalarial resistance in the Democratic Republic of the Congo [115•, $211 \bullet \cdot, 212]$. Methods for estimating the propagation of resistance in these high-transmission settings require further development before being routinely deployed.

The continual surveillance of parasite population by genomics has the potential to help identify new mechanisms of resistance early in the course of drug deployment and formulary changes. In combination with other genomics-based approaches, this could hasten the recognition of concerning signals for antimalarial resistance in parasite populations. Recent studies using a combination of in vitro resistance evolution and whole genome sequencing (IVIEWGA) have started to map the P. falciparum "resistome" [213••, 214]. This approach identified new potential resistance mechanisms and possible drug targets. Several of the putative genes associated with resistance have now been shown to have signals of selection in population genomics studies [190, 211••]. Meanwhile, the identification of novel mechanisms of resistance and new artemisinin-resistance candidates is under investigation using IVIEWGA [215-217]. There is an ongoing need to identify alternative resistance mechanisms in subSaharan Africa where clinical signs of partial resistance (prolonged parasite clearance) have been described without evidence of $p f k 13$ mutations [60•, 218].

Advances in gene editing have also proven pivotal. The ability to deliver single point mutations and gene deletions with modern gene editing platforms, such as zinc finger endonuclease and CRISPR/Cas9, has accelerated and expanded genetic studies of antimalarial resistance [219-224]. Gene editing was key to understanding the functional impacts of 
individual mutations in $p f k 13$, a significant achievement given the complex genetic backdrop of the gene which has a high degree of underlying variations with little to no functional roles [61, 110, 225]. Functional genomics has also been used to validate resistance mutations for other antimalarials including CQ, PPQ, ozonides, and piperazine compounds [226-229, $230 \bullet \cdot, 231]$. While much of this work has been in $P$. falciparum, gene-editing technologies are also being applied to other human malaria parasites [232]. Current approaches, however, are limited by low efficiency and high numbers of unexpected recombination events. Gene editing in Plasmodium spp. is uniquely challenging due to the parasites' AT-rich genome, lack of canonical DNA repair pathways, absence of nuclear genomic RNAi, and attrition of transfecting plasmids during cell division [233-235]. Over the last couple of years, innovations in CRISPR/Cas9-based tools in P. falciparum and other species have begun to overcome these challenges [236•, 237].

\section{Conclusion}

Centuries before Paul Erlich ushered in the era of antimicrobial chemotherapy, malaria remedies were gotten by our ancestors from Cinchona and Artemisia plant species, original sources of what remain the two most widely used antimalarial pharmacophores. Signs of antimalarial drug resistance were first evident over 100 years ago, and a punctuated march of drug resistance across the globe proceeded from almost every new introduction of antimalarials in the years that followed $[19,31]$. Today, we have increasingly sophisticated tools for surveilling, containing, and combatting the emergence, spread, and harms of antimalarial drug resistance. Yet malaria control is backsliding. The contravening forces of political instability, donor fatigue, climate change, and, recently, competing public health priorities and economic recession caused by the coronavirus pandemic are complicit. The expansion of drug resistance to ACTs poses at least an equal threat. Updates in drug development, clinical pharmacology, parasite genomics, transcriptomics, and bioinformatics, with their efficient and judicious application, can reclaim lost ground in the WHO Global Technical Strategy. A forward-looking agenda that helps preserve inasmuch as possible the efficacy of current agents through increased antimalarial stewardship, speeds the arrival of new agents and treatment regimens, and fully exploits nimble and scalable genomics-based platforms for discovery and surveillance can replace vulnerability with opportunity.

\section{Declarations}

Conflict of Interest The authors declare no competing interests.
Human and Animal Rights and Informed Consent This article does not contain any studies with human or animal subjects performed by any of the authors.

\section{References}

Papers of particular interest, published recently, have been highlighted as:

- Of importance

•- Of major importance

1. World Health Organization. Official records of the World Health Organization No. 184, 23rd World Health Assembly: Geneva, World Health Organization; 1970.

2. Najera JA, Gonzalez-Silva M, Alonso PL. Some lessons for the future from the Global Malaria Eradication Programme (19551969). PLoS Med. 2011;8(1):e1000412.

3. World Health Organization Expert Committee on Malaria Technical Report Series No. 357: World Health Organization Expert Committee on Malaria 13th Report. Geneva: World Health Organization; 1967.

4. World Health Organization. Global technical strategy for malaria 2016-2030. Geneva: World Health Organization; 2016.

5. World Health Organization. World malaria report. Geneva: WHO Global Malaria Programme; 2019.

6. World Health Organization. High burden to high impact: a targetted malaria response. Geneva: World Health Organization; 2019.

7. Hogan AB, Jewell BL, Sherrard-Smith E, Vesga JF, Watson OJ, Whittaker C, et al. Potential impact of the COVID-19 pandemic on HIV, tuberculosis, and malaria in low-income and middleincome countries: a modelling study. Lancet Glob Health. 2020;8(9):e1132-e41 Modeling study that projects an increase in malaria mortality by up to $36 \%$ due to the COVID-19 pandemic.

8. Sherrard-Smith E, Hogan AB, Hamlet A, Watson OJ, Whittaker $\mathrm{C}$, Winskill $\mathrm{P}$, et al. The potential public health consequences of COVID-19 on malaria in Africa. Nat Med. 2020;26(9):1411-6 Models the disruption of malaria prevention activities due to COVID-19 and predicts a doubling of malaria burden in 2020.

9. World Health Organization. Guidelines for the treatment of malaria. Geneva: World Health Organization; 2015.

10. Dondorp A, Nosten F, Stepniewska K, Day N, White N. South East Asian Quinine Artesunate Malaria Trial g. Artesunate versus quinine for treatment of severe falciparum malaria: a randomised trial. Lancet. 2005;366(9487):717-25.

11. Dondorp AM, Fanello CI, Hendriksen IC, Gomes E, Seni A, Chhaganlal KD, et al. Artesunate versus quinine in the treatment of severe falciparum malaria in African children (AQUAMAT): an open-label, randomised trial. Lancet. 2010;376(9753):164757.

12. Nosten F, van Vugt M, Price R, Luxemburger C, Thway KL, Brockman A, et al. Effects of artesunate-mefloquine combination on incidence of Plasmodium falciparum malaria and mefloquine resistance in western Thailand: a prospective study. Lancet. 2000;356(9226):297-302.

13. Khanh NX, de Vries PJ, Ha LD, van Boxtel CJ, Koopmans R, Kager PA. Declining concentrations of dihydroartemisinin in plasma during 5-day oral treatment with artesunate for Falciparum malaria. Antimicrob Agents Chemother. 1999;43(3):690-2. 
14. Ashley EA, Dhorda M, Fairhurst RM, Amaratunga C, Lim P, Suon S, et al. Spread of artemisinin resistance in Plasmodium falciparum malaria. N Engl J Med. 2014;371(5):411-23.

15. Worldwide Antimalarial Resistance Network Parasite Clearance Study Group. Baseline data of parasite clearance in patients with falciparum malaria treated with an artemisinin derivative: an individual patient data meta-analysis. Malaria Journal. 2015;14:359.

16. Swellengrebel HH. Report on investigation into malaria in the Union of South Africa, 1930-1931. J Med Assoc South Afr (BMA). 1931.

17. Wallace RB. Mass treatment with Atebrin and Plasmochin Simplex, 1933. The Malayan Medical Journal. 1934;VIII(3): 145-62.

18. Barber MA, Rice JB, Brown JY. Malaria studies on the Firestone rubber plantation in Liberia, West Africa. The American Journal of Hygiene. 1932;15(3):601-33.

19. Nocht $B$, Werner H. Observations on relative quinine resistance in malaria from Brazil. German Medical Weekly. 1910;36:1557-60.

20. Moore DV, Lanier JE. Observations on two Plasmodium falciparum infections with an abnormal response to chloroquine. Am J Trop Med Hyg. 1961;10:5-9.

21. Harinasuta T, Migasen S, Bunnag D. Chloroquine resistance in Plasmodium falciparum in Thailand. UNESCO 1st Regional Symposium on Scientific Knowledge of Tropical Parasites. Singapore: University of Singapore; 1962.

22. Payne D. Spread of chloroquine resistance in Plasmodium falciparum. Parasitoogy Today. 1987;3(8):241-6.

23. Ronn AM, Msangeni HA, Mhina J, Wernsdorfer WH, Bygbjerg IC. High level of resistance of Plasmodium falciparum to sulfadoxine-pyrimethamine in children in Tanzania. Trans R Soc Trop Med Hyg. 1996;90(2):179-81.

24. Clyde DF. Observations on monthly pyrimethamine (daraprim) prophylaxis in an East African village. East Afr Med J. 1954;31(2):41-6.

25. Clyde DF, Shute GT. Resistance of Plasmodium falciparum in Tanganyika to pyrimethamine administered at weekly intervals. Trans R Soc Trop Med Hyg. 1957;51(6):505-13.

26. Greenberg AE, Ntumbanzondo M, Ntula N, Mawa L, Howell J, Davachi F. Hospital-based surveillance of malaria-related paediatric morbidity and mortality in Kinshasa, Zaire. Bull World Health Organization. 1989;67(2):189-96 The authors describe experiments that employed linear donor templates to reduce the frequency of unexpected recombinations that typically complicate CRISPR/Cas9 applications in Plasmodium gene editing.

27. Khoromana CO, Campbell CC, Wirima JJ, Heymann DL. In vivo efficacy of chloroquine treatment for Plasmodium falciparum in Malawian children under five years of age. Am J Trop Med Hyg. 1986;35(3):465-71.

28. Trape JF, Pison G, Preziosi MP, Enel C. Desgrees du Lou A, Delaunay $\mathrm{V}$, et al. Impact of chloroquine resistance on malaria mortality. C R Acad Sci III. 1998;321(8):689-97.

29. Kilama WL, Kihamia CM. Malaria. In: Mwaluko GMP, Kilama WL, Mandara PM, Murru M, Macpherson CNL, editors. Health and disease in Tanzania. London: Harper Collins; 1991. p. 11732.

30. Trape JF. The public health impact of chloroquine resistance in Africa. Am J Trop Med Hyg. 2001;64(1-2 Suppl):12-7.

31. Blasco B, Leroy D, Fidock DA. Antimalarial drug resistance: linking Plasmodium falciparum parasite biology to the clinic. Nat Med. 2017;23(8):917-28.

32. Bosman A, Mendis KN. A major transition in malaria treatment: the adoption and deployment of artemisinin-based combination therapies. Am J Trop Med Hyg. 2007;77(6 Suppl):193-7.

33. Rogers WO, Sem R, Tero T, Chim P, Lim P, Muth S, et al. Failure of artesunate-mefloquine combination therapy for uncomplicated
Plasmodium falciparum malaria in southern Cambodia. Malar J. 2009;8:10.

34. Dondorp AM, Nosten F, Yi P, Das D, Phyo AP, Tarning J, et al. Artemisinin resistance in Plasmodium falciparum malaria. N Engl J Med. 2009;361(5):455-67.

35.• van der Pluijm RW, Tripura R, Hoglund RM, Pyae Phyo A, Lek D, Ul Islam A, et al. Triple artemisinin-based combination therapies versus artemisinin-based combination therapies for uncomplicated Plasmodium falciparum malaria: a multicentre, open-label, randomised clinical trial. Lancet. 2020;395(10233):1345-60 A large multicenter, open-label randomized controlled clinical trial spanning Southeast Asia and Africa demonstrating the safety and efficacy of triple artemisinin-based combination therapy (TACT) regimens, a potential stopgap measure for treatment of malaria that is resistant to conventional ACT regimens.

36. Amaratunga C, Lim P, Suon S, Sreng S, Mao S, Sopha C, et al. Dihydroartemisinin-piperaquine resistance in Plasmodium falciparum malaria in Cambodia: a multisite prospective cohort study. Lancet Infect Dis. 2016;16(3):357-65.

37. Phuc BQ, Rasmussen C, Duong TT, Dong LT, Loi MA, Menard $\mathrm{D}$, et al. Treatment failure of dihydroartemisinin/piperaquine for Plasmodium falciparum malaria, Vietnam. Emerg Infect Dis. 2017;23(4):715-7.

38. Phyo AP, Ashley EA, Anderson TJC, Bozdech Z, Carrara VI, Sriprawat K, et al. Declining efficacy of artemisinin combination therapy against $\mathrm{P}$. falciparum malaria on the Thai-Myanmar border (2003-2013): the role of parasite genetic factors. Clin Infect Dis. 2016;63(6):784-91.

39. Thanh NV, Thuy-Nhien N, Tuyen NT, Tong NT, Nha-Ca NT, Dong LT, et al. Rapid decline in the susceptibility of Plasmodium falciparum to dihydroartemisinin-piperaquine in the south of Vietnam. Malar J. 2017;16(1):27.

40. van der Pluijm RW, Imwong M, Chau NH, Hoa NT, Thuy-Nhien NT, Thanh NV, et al. Determinants of dihydroartemisininpiperaquine treatment failure in Plasmodium falciparum malaria in Cambodia, Thailand, and Vietnam: a prospective clinical, pharmacological, and genetic study. Lancet Infect Dis. 2019;19(9): 952-61.

41. World Health Organization. Methods of surveillance of antimalarial drug efficacy. Geneva: Global Malaria Programme; 2009.

42. Leang R, Taylor WR, Bouth DM, Song L, Tarning J, Char MC, et al. Evidence of Plasmodium falciparum malaria multidrug resistance to artemisinin and piperaquine in western Cambodia: Dihydroartemisinin-Piperaquine Open-Label Multicenter Clinical Assessment. Antimicrob Agents Chemother. 2015;59(8):4719-26.

43. Leang R, Barrette A, Bouth DM, Menard D, Abdur R, Duong S, et al. Efficacy of dihydroartemisinin-piperaquine for treatment of uncomplicated Plasmodium falciparum and Plasmodium vivax in Cambodia, 2008 to 2010. Antimicrob Agents Chemother. 2013;57(2):818-26.

44. Thriemer K, Hong NV, Rosanas-Urgell A, Phuc BQ, Ha do M, Pockele E, et al. Delayed parasite clearance after treatment with dihydroartemisinin-piperaquine in Plasmodium falciparum malaria patients in central Vietnam. Antimicrob Agents Chemother. 2014;58(12):7049-55.

45. Mishra N, Kaitholia K, Srivastava B, Shah NK, Narayan JP, Dev $\mathrm{V}$, et al. Declining efficacy of artesunate plus sulphadoxinepyrimethamine in northeastern India. Malar J. 2014;13:284.

46. Vreden SG, Jitan JK, Bansie RD, Adhin MR. Evidence of an increased incidence of day 3 parasitaemia in Suriname: an indicator of the emerging resistance of Plasmodium falciparum to artemether. Mem Inst Oswaldo Cruz. 2013;108(8):968-73.

47. Plucinski MM, Talundzic E, Morton L, Dimbu PR, Macaia AP, Fortes F, et al. Efficacy of artemether-lumefantrine and 
dihydroartemisinin-piperaquine for treatment of uncomplicated malaria in children in Zaire and Uige Provinces, angola. Antimicrob Agents Chemother. 2015;59(1):437-43.

48. Dieye B, Affara M, Sangare L, Joof F, Ndiaye YD, Gomis JF, et al. West Africa International Centers of Excellence for Malaria Research: drug resistance patterns to artemether-lumefantrine in Senegal, Mali, and The Gambia. Am J Trop Med Hyg. 2016;95(5):1054-60.

49. Woodrow CJ, Haynes RK, Krishna S. Artemisinins. Postgrad Med J. 2005;81(952):71-8.

50. Rieckmann KH, Davis DR, Hutton DC. Plasmodium vivax resistance to chloroquine? Lancet. 1989;2(8673):1183-4.

51. Whitby M, Wood G, Veenendaal JR, Rieckmann K. Chloroquineresistant Plasmodium vivax. Lancet. 1989;2(8676):1395.

52. Maguire JD, Sumawinata IW, Masbar S, Laksana B, Prodjodipuro $\mathrm{P}$, Susanti I, et al. Chloroquine-resistant Plasmodium malariae in south Sumatra. Indonesia. Lancet. 2002;360(9326):58-60.

53. Hupalo DN, Luo Z, Melnikov A, Sutton PL, Rogov P, Escalante A, et al. Population genomics studies identify signatures of global dispersal and drug resistance in Plasmodium vivax. Nat Genet. 2016;48(8):953-8.

54. Van Hong N, Amambua-Ngwa A, Tuan NQ, Cuong do D, Giang NT, Van Dung N, et al. Severe malaria not responsive to artemisinin derivatives in man returning from Angola to Vietnam. Emerg Infect Dis. 2014;20(7):1199-202.

55. Sutherland CJ, Lansdell P, Sanders M, Muwanguzi J, van Schalkwyk DA, Kaur H, et al. pfk13-independent treatment failure in four imported cases of Plasmodium falciparum malaria treated with artemether-lumefantrine in the United Kingdom. Antimicrob Agents Chemother. 2017;61(3):e02382-16.

56. Sonden K, Wyss K, Jovel I, da Silva Vieira A, Pohanka A, Asghar $\mathrm{M}$, et al. High rate of treatment failures in nonimmune travelers treated with artemether-lumefantrine for uncomplicated Plasmodium falciparum malaria in Sweden: retrospective comparative analysis of effectiveness and case series. Clin Infect Dis. 2017;64(2):199-206.

57. Russo G, L'Episcopia M, Menegon M, Souza SS, Dongho BGD, Vullo V, et al. Dihydroartemisinin-piperaquine treatment failure in uncomplicated Plasmodium falciparum malaria case imported from Ethiopia. Infection. 2018;46(6):867-70 Case report of genotype-confirmed treatment failure of dihydroartemisininpiperaquine in a returned Italian traveler from Ethiopia with $P$. falciparum malaria.

58. Repetto EC, Traverso A, Giacomazzi CG. Possible clinical failure of artemether-lumefantrine in an italian traveler with uncomplicated falciparum malaria. Mediterr J Hematol Infect Dis. 2011;3(1): e2011041.

59. Lu F, Culleton R, Zhang M, Ramaprasad A, von Seidlein L, Zhou $\mathrm{H}$, et al. Emergence of indigenous artemisinin-resistant Plasmodium falciparum in Africa. N Engl J Med. 2017;376(10): 991-3.

60. WWARN Genotype-Phenotype Study Group, et al. BMC Med. 2019;17(1):1. Meta-analysis of 3,250 patients linking 6 previously described and 15 newly described pfk 13 mutations to prolonged parasite clearance in Southeast Asia. However, none of the isolates from the four represented African countries showed any association between $p f k 13$ alleles and parasite clearance.

61.• Uwimana A, Legrand E, Stokes BH, Ndikumana JM, Warsame M, Umulisa N, et al. Emergence and clonal expansion of in vitro artemisinin-resistant Plasmodium falciparum kelch13 R561H mutant parasites in Rwanda. Nat Med. 2020;26:1602-8 Presents evidence, from drug efficacy studies of ACTs in Rwanda, of the de novo emergence of $p f k 13$-mediated artemisinin resistance.
62. Das S, Saha B, Hati AK, Roy S, et al. N Engl J Med. 2018;379(20):1962-4 Short correspondence reporting prolonged parasite clearance and increased ex vivo ringstage survival associated with pfk 13 mutants G625R and R539T from 5 out of 136 Indian patients with uncomplicated falciparum malaria treated with AS-SP.

63. Mathieu LC, Cox H, Early AM, Mok S, Lazrek Y, Paquet JC, et al. Local emergence in Amazonia of Plasmodium falciparum k13 C580Y mutants associated with in vitro artemisinin resistance. Elife. 2020;9:e51015 The authors report de novo emergence of $p f k 13 \mathrm{C580Y}$ in Guyana, South America at a frequency of $1.6 \%$ (14/854 isolates collected 2016-17). In vitro growth competition assays supported a fitness cost associated with this and the R539T mutations.

64. Kublin JG, Cortese JF, Njunju EM, Mukadam RA, Wirima JJ, Kazembe PN, et al. Reemergence of chloroquine-sensitive Plasmodium falciparum malaria after cessation of chloroquine use in Malawi. J Infect Dis. 2003;187(12):1870-5.

65. Laufer MK, Thesing PC, Eddington ND, Masonga R, Dzinjalamala FK, Takala SL, et al. Return of chloroquine antimalarial efficacy in Malawi. N Engl J Med. 2006;355(19):1959-66.

66. Mharakurwa S, Matsena-Zingoni Z, Mudare N, Matimba C, Gara TX, Makuwaza A, et al. Steep rebound of chloroquine sensitive Plasmodium falciparum in Zimbabwe. J Infect Dis. 2020;223(2): 306-9.

67. Mwai L, Ochong E, Abdirahman A, Kiara SM, Ward S, Kokwaro $\mathrm{G}$, et al. Chloroquine resistance before and after its withdrawal in Kenya. Malar J. 2009;8:106.

68. Laufer MK, Takala-Harrison S, Dzinjalamala FK, Stine OC, Taylor TE, Plowe CV. Return of chloroquine-susceptible falciparum malaria in Malawi was a reexpansion of diverse susceptible parasites. J Infect Dis. 2010;202(5):801-8.

69. Mwanza S, Joshi S, Nambozi M, Chileshe J, Malunga P, Kabuya $\mathrm{JB}$, et al. The return of chloroquine-susceptible Plasmodium falciparum malaria in Zambia. Malar J. 2016;15(1):584.

70. Ndam NT, Basco LK, Ngane VF, Ayouba A, Ngolle EM, Deloron $\mathrm{P}$, et al. Reemergence of chloroquine-sensitive pfcrt K76 Plasmodium falciparum genotype in southeastern Cameroon. Malar J. 2017;16(1):130.

71. Asua V, Vinden J, Conrad MD, Legac J, Kigozi SP, Kamya MR, et al. Changing Molecular Markers of antimalarial drug sensitivity across Uganda. Antimicrob Agents Chemother. 2019;63(3): e01818-18.

72. Wolcott GB. Chromosomes of the four species of human malaria, studied by phase microscopy. Journal of Heredity. 1955;46(2):537.

73. Goodman CD, Siregar JE, Mollard V, Vega-Rodriguez J, Syafruddin D, Matsuoka H, et al. Parasites resistant to the antimalarial atovaquone fail to transmit by mosquitoes. Science. 2016;352(6283):349-53.

74. Conrad MD, Rosenthal PJ. Antimalarial drug resistance in Africa: the calm before the storm? Lancet Infect Dis. 2019;19(10):e338 e51.

75. Ross LS, Fidock DA, et al. Cell Host Microbe. 2019;26(1):35-47 This review compares and contrasts the genetics, molecular mechanisms, and historical usage of four major antimalarials: CQ, SP, PPQ and artemisinin derivatives.

76. Mbengue A, Bhattacharjee S, Pandharkar T, Liu H, Estiu G, Stahelin RV, et al. A molecular mechanism of artemisinin resistance in Plasmodium falciparum malaria. Nature. 2015;520(7549):683-7.

77. Mok S, Ashley EA, Ferreira PE, Zhu L, Lin Z, Yeo T, et al. Drug resistance. Population transcriptomics of human malaria parasites reveals the mechanism of artemisinin resistance. Science. 2015;347(6220):431-5. 
78. Wicht KJ, Mok S, Fidock DA. Molecular mechanisms of drug resistance in Plasmodium falciparum malaria. Annu Rev Microbiol. 2020;74:431-54 This review discusses the genetics and molecular mechanisms of $\boldsymbol{P}$. falciparum resistance to aminoquinolines mainly via $p f c r t$ and $p f m d r 1$ mutations and artemisinin derivatives via $p f k 13$-mediated resistance and the unfolded protein response pathway.

79. Price RN, von Seidlein L, Valecha N, Nosten F, Baird JK, White NJ. Global extent of chloroquine-resistant Plasmodium vivax: a systematic review and meta-analysis. Lancet Infect Dis. 2014;14(10):982-91.

80. Price RN. Improving the radical cure of Plasmodium vivax malaria. Am J Trop Med Hyg. 2014;91(1):3-4.

81. Baird JK, Leksana B, Masbar S, Fryauff DJ, Sutanihardja MA. Suradi, et al. Diagnosis of resistance to chloroquine by Plasmodium vivax: timing of recurrence and whole blood chloroquine levels. Am J Trop Med Hyg. 1997;56(6):621-6.

82. Sumawinata IW, Bernadeta LB, Sutamihardja A, Purnomo SB, et al. Very high risk of therapeutic failure with chloroquine for uncomplicated Plasmodium falciparum and $P$. vivax malaria in Indonesian Papua. Am J Trop Med Hyg. 2003;68(4):416-20.

83. Lu F, Wang B, Cao J, Sattabongkot J, Zhou H, Zhu G, et al. Prevalence of drug resistance-associated gene mutations in Plasmodium vivax in Central China. Korean J Parasitol. 2012;50(4):379-84.

84. Chehuan YF, Costa MR, Costa JS, Alecrim MG, Nogueira F, Silveira $\mathrm{H}$, et al. In vitro chloroquine resistance for Plasmodium vivax isolates from the Western Brazilian Amazon. Malar J. 2013;12:226

85. Khattak AA, Venkatesan M, Khatoon L, Ouattara A, Kenefic LJ, Nadeem MF, et al. Prevalence and patterns of antifolate and chloroquine drug resistance markers in Plasmodium vivax across Pakistan. Malar J. 2013;12:310.

86. Goncalves LA, Cravo P, Ferreira MU. Emerging Plasmodium vivax resistance to chloroquine in South America: an overview. Mem Inst Oswaldo Cruz. 2014;109(5):534-9.

87. Marques MM, Costa MR, Santana Filho FS, Vieira JL, Nascimento MT, Brasil LW, et al. Plasmodium vivax chloroquine resistance and anemia in the western Brazilian Amazon. Antimicrob Agents Chemother. 2014;58(1):342-7.

88. Pirahmadi S, Talha BA, Nour BY, Zakeri S. Prevalence of mutations in the antifolates resistance-associated genes (dhfr and dhps) in Plasmodium vivax parasites from Eastern and Central Sudan. Infect Genet Evol. 2014;26:153-9.

89. Anez A, Moscoso M, Laguna A, Garnica C, Melgar V, Cuba M, et al. Resistance of infection by Plasmodium vivax to chloroquine in Bolivia. Malar J. 2015;14:261.

90. Golassa L, Erko B, Baliraine FN, Aseffa A, Swedberg G. Polymorphisms in chloroquine resistance-associated genes in Plasmodium vivax in Ethiopia. Malar J. 2015;14:164.

91. Thanh PV, Hong NV, Van NV, Louisa M, Baird K, Xa NX, et al. Confirmed Plasmodium vivax resistance to chloroquine in central Vietnam. Antimicrob Agents Chemother. 2015;59(12):7411-9.

92. Musset L, Heugas C, Naldjinan R, Blanchet D, Houze P, Abboud $\mathrm{P}$, et al. Emergence of Plasmodium vivax resistance to chloroquine in French Guiana. Antimicrob Agents Chemother. 2019;63(11): e02116-8 A study out of French Guiana that identified $\boldsymbol{P}$. vivax CQ treatment failures in 8 out of 172 patients among which 2 appeared to have treatment failure not explained by subtherapeutic drug concentrations. These were attributed to CQ resistance, although no polymorphism or copy number variation was identified in pvmdr1 or pvcrt-o.

93. Pearson RD, Amato R, Auburn S, Miotto O, Almagro-Garcia J, Amaratunga $\mathrm{C}$, et al. Genomic analysis of local variation and recent evolution in Plasmodium vivax. Nat Genet. 2016;48(8): 959-64.
94. Djimde A, Doumbo OK, Steketee RW, Plowe CV. Application of a molecular marker for surveillance of chloroquine-resistant falciparum malaria. Lancet. 2001;358(9285):890-1.

95. Fidock DA, Nomura T, Talley AK, Cooper RA, Dzekunov SM, Ferdig MT, et al. Mutations in the P. falciparum digestive vacuole transmembrane protein PfCRT and evidence for their role in chloroquine resistance. Mol Cell. 2000;6(4):861-71.

96. Nomura T, Carlton JM, Baird JK, del Portillo HA, Fryauff DJ, Rathore D, et al. Evidence for different mechanisms of chloroquine resistance in 2 Plasmodium species that cause human malaria. J Infect Dis. 2001;183(11):1653-61.

97. Sa JM, Kaslow SR, Moraes Barros RR, Brazeau NF, Parobek $\mathrm{CM}$, Tao D, et al. Plasmodium vivax chloroquine resistance links to pvert transcription in a genetic cross. Nat Commun. 2019;10(1): 4300 Genetic crosses of $\boldsymbol{P}$. vivax to evaluate CQ resistance identified, through linkage mapping of drug-tolerant parasites and transcriptional analysis, upregulated pvcrt expression as a potential mechanism of $C Q$ resistance.

98. Fernandez-Becerra C, Pinazo MJ, Gonzalez A, Alonso PL, del Portillo HA, Gascon J. Increased expression levels of the pvcrt-o and pvmdrl genes in a patient with severe Plasmodium vivax malaria. Malar J. 2009;8:55.

99. Melo GC, Monteiro WM, Siqueira AM, Silva SR, Magalhaes BM, Alencar AC, et al. Expression levels of pvcrt-o and pvmdr1 are associated with chloroquine resistance and severe Plasmodium vivax malaria in patients of the Brazilian Amazon. PLoS One. 2014;9(8):e105922.

100. World Health Organization. Assessment and monitoring of antimalarial drug efficacy for the treatment of uncomplicated falciparum malaria. 2003.

101. World Health Organization. Methods and techniques for clinical trials on antimalarial drug efficacy: genotyping to identify parasite populations. Amsterdam: WHO Global Malaria Programme; 2007.

102. Duru V, Khim N, Leang R, Kim S, Domergue A, Kloeung N, et al. Plasmodium falciparum dihydroartemisinin-piperaquine failures in Cambodia are associated with mutant K13 parasites presenting high survival rates in novel piperaquine in vitro assays: retrospective and prospective investigations. BMC Med. 2015;13:305.

103. Witkowski B, Amaratunga C, Khim N, Sreng S, Chim P, Kim S, et al. Novel phenotypic assays for the detection of artemisininresistant Plasmodium falciparum malaria in Cambodia: in-vitro and ex-vivo drug-response studies. Lancet Infect Dis. 2013;13(12):1043-9.

104. Prosser C, Meyer W, Ellis J, Lee R. Evolutionary ARMS race: antimalarial resistance molecular surveillance. Trends Parasitol. 2018;34(4):322-34.

105. Ippolito MM, Pringle JC, Siame M, Katowa B, Aydemir O, Oluoch PO, et al. Therapeutic efficacy of artemetherlumefantrine for uncomplicated falciparum malaria in northern Zambia. Am J Trop Med Hyg. 2020;103(6):2224-32.

106. Yeka A, Wallender E, Mulebeke R, Kibuuka A, Kigozi R, Bosco A, et al. Comparative efficacy of artemether-lumefantrine and dihydroartemisinin-piperaquine for the treatment of uncomplicated malaria in Ugandan children. J Infect Dis. 2019;219(7):111220.

107. World Health Organization. The Mekong Malaria Elimination Programme. Countries of the Greater Mekong are stepping up to end malaria. 2018.

108. Ariey F, Witkowski B, Amaratunga C, Beghain J, Langlois AC, Khim N, et al. A molecular marker of artemisinin-resistant Plasmodium falciparum malaria. Nature. 2014;505(7481):50-5.

109. Miotto O, Amato R, Ashley EA, MacInnis B, Almagro-Garcia J, Amaratunga $\mathrm{C}$, et al. Genetic architecture of artemisinin-resistant Plasmodium falciparum. Nat Genet. 2015;47(3):226-34. 
110. Taylor SM, Parobek CM, DeConti DK, Kayentao K, Coulibaly $\mathrm{SO}$, Greenwood BM, et al. Absence of putative artemisinin resistance mutations among Plasmodium falciparum in sub-Saharan Africa: a molecular epidemiologic study. J Infect Dis. 2015;211(5):680-8.

111. Kamau E, Campino S, Amenga-Etego L, Drury E, Ishengoma D, Johnson K, et al. K13-propeller polymorphisms in Plasmodium falciparum parasites from sub-Saharan Africa. J Infect Dis. 2015;211(8):1352-5.

112. Chenet SM, Akinyi Okoth S, Huber CS, Chandrabose J, Lucchi NW, Talundzic E, et al. Independent emergence of the Plasmodium falciparum Kelch propeller domain mutant allele C580Y in Guyana. J Infect Dis. 2016;213(9):1472-5.

113. Tacoli C, Gai PP, Bayingana C, Sifft K, Geus D, Ndoli J, et al. Artemisinin resistance-associated K13 polymorphisms of Plasmodium falciparum in Southern Rwanda, 2010-2015. Am J Trop Med Hyg. 2016;95(5):1090-3.

114. Asua V, Conrad MD, Aydemir O, Duvalsaint M, Legac J, Duarte E, et al. Changing prevalence of potential mediators of aminoquinoline, antifolate, and artemisinin resistance across Uganda. JID. 2020.

115. Moser KA, Madebe RA, Aydemir O, Chiduo MG, Mandara CI, Rumisha SF, et al. Describing the current status of Plasmodium falciparum population structure and drug resistance within mainland Tanzania using molecular inversion probes. Mol Ecol. 2020;30:100-13 High-throughput Plasmodium genomics of > 1000 clinical isolates from Tanzania distinguished geographically distinct population clusters and identified antimalarial drug resistance mutations including $p f k 13 \mathrm{R561H}$ and additional $p f k 13$ variants with undetermined significance.

116. Gutierrez MM, Pillai G, Felix S, Romero F, Onyango KO, Owusu-Agyei S, et al. Building capability for clinical pharmacology research in sub-Saharan Africa. Clin Pharmacol Ther. 2017;102(5):786-95.

117. Bhatt S, Weiss DJ, Cameron E, Bisanzio D, Mappin B, Dalrymple $\mathrm{U}$, et al. The effect of malaria control on Plasmodium falciparum in Africa between 2000 and 2015. Nature. 2015;526(7572):20711.

118. Krishna S. Triple artemisinin-containing combination antimalarial treatments should be implemented now to delay the emergence of resistance: the case against. Malar J. 2019;18(1): 339.

119. White NJ. Triple artemisinin-containing combination anti-malarial treatments should be implemented now to delay the emergence of resistance. Malar J. 2019;18(1):338.

120. Martin SK, Oduola AM, Milhous WK. Reversal of chloroquine resistance in Plasmodium falciparum by verapamil. Science. 1987;235(4791):899-901.

121. Kshirsagar NA, Gogtay NJ, Moran D, Utz G, Sethia A, Sarkar S, et al. Treatment of adults with acute uncomplicated malaria with azithromycin and chloroquine in India, Colombia, and Suriname. Res Rep Trop Med. 2017;8:85-104.

122. Barnes KI, Watkins WM, White NJ. Antimalarial dosing regimens and drug resistance. Trends Parasitol. 2008;24(3):127-34.

123. Moore BR, Davis TM. Updated pharmacokinetic considerations for the use of antimalarial drugs in pregnant women. Expert Opin Drug Metab Toxicol. 2020;16(9):741-58.

124. WorldWide Antimalarial Resistance Network DPSG. The effect of dosing regimens on the antimalarial efficacy of dihydroartemisinin-piperaquine: a pooled analysis of individual patient data. PLoS Med. 2013;10(12):e1001564 discussion e.

125. Anyanwu PE, Fulton J, Evans E, Paget T. Exploring the role of socioeconomic factors in the development and spread of antimalarial drug resistance: a qualitative study. Malar J. 2017;16(1): 203.
126. Nayyar GML, Breman JG, Mackey TK, Clark JP, Hajjou M, Littrell M, et al. Falsified and substandard drugs: stopping the pandemic. Am J Trop Med Hyg. 2019;100(5):1058-65.

127. Ozawa S, Evans DR, Bessias S, Haynie DG, Yemeke TT, Laing SK, et al. Prevalence and estimated economic burden of substandard and falsified medicines in low- and middle-income countries: a systematic review and meta-analysis. JAMA Netw Open. 2018;1(4):e181662.

128. Beshir KB, Sutherland CJ, Sawa P, Drakeley CJ, Okell L, Mweresa CK, et al. Residual Plasmodium falciparum parasitemia in Kenyan children after artemisinin-combination therapy is associated with increased transmission to mosquitoes and parasite recurrence. J Infect Dis. 2013;208(12):2017-24.

129. Pollitt LC, Huijben S, Sim DG, Salathe RM, Jones MJ, Read AF. Rapid response to selection, competitive release and increased transmission potential of artesunate-selected Plasmodium chabaudi malaria parasites. PLoS Pathog. 2014;10(4):e1004019.

130. Ippolito MM, Johnson J, Mullin C, Mallow C, Morgan N, Wallender E, et al. The relative effects of artemetherlumefantrine and non-artemisinin antimalarials on gametocyte carriage and transmission of Plasmodium falciparum: a systematic review and meta-analysis. Clin Infect Dis. 2017;65(3):486-94.

131. Sinclair D, Zani B, Donegan S, Olliaro P, Garner P. Artemisininbased combination therapy for treating uncomplicated malaria. Cochrane Database Syst Rev. 2009;(3):CD007483.

132. World Health Organization and Global Malaria Programme. Updated WHO policy recommendation: single dose primaquine as a gametocytocide in Plasmodium falciparum malaria. Geneva: WHO; 2012.

133.• Stepniewska K, Humphreys GS, Goncalves BP, Craig E, Gosling $\mathrm{R}$, Guerin PJ, et al. Efficacy of single dose primaquine with artemisinin combination therapy on $P$. falciparum gametocytes and transmission: a WWARN individual patient meta-analysis. J Infect Dis. 2020; Meta-analysis of $\mathbf{2 5 7 4}$ trial participants from 14 separate studies supported the efficacy of single low dose primaquine in blocking $\boldsymbol{P}$. falciparum transmission, as measured by gametocyte carriage and mosquito transmission assays.

134. Chen IT, Gosling RD. Targeting Plasmodium falciparum transmission with primaquine: same efficacy, improved safety with a lower dose? Expert Rev Clin Pharmacol. 2014;7(6):681-6.

135. Raman J, Allen E, Workman L, Mabuza A, Swanepoel H, Malatje $\mathrm{G}$, et al. Safety and tolerability of single low-dose primaquine in a low-intensity transmission area in South Africa: an open-label, randomized controlled trial. Malar J. 2019;18(1):209.

136. Mwaiswelo R, Ngasala BE, Jovel I, Gosling R, Premji Z, Poirot E, et al. Safety of a single low-dose of primaquine in addition to standard artemether-lumefantrine regimen for treatment of acute uncomplicated Plasmodium falciparum malaria in Tanzania. Malar J. 2016;15:316.

137. Avalos S, Mejia RE, Banegas E, Salinas C, Gutierrez L, Fajardo $\mathrm{M}$, et al. G6PD deficiency, primaquine treatment, and risk of haemolysis in malaria-infected patients. Malar J. 2018;17(1):415.

138. World Health Organization. Intermittent preventive treatment of malaria in pregnancy using sulfadoxin-pyrimethamine (IPTp-SP). Geneva: WHO; 2012.

139. World Health Organization. Seasonal malaria chemoprevention (SMC) for Plasmodium falciparum malaria control in highly seasonal transmission areas of the Sahel sub-region in Africa. Geneva: World Health Organization; 2012.

140. World Health Organization. WHO policy recommendation on intermittent preventive treatment during infancy with sulfadoxinepyrimethamine (SP-IPTi) for Plasmodium falciparum malaria control in Africa. Geneva: World Health Organization; 2010. 
141. Wilson AL, Taskforce IP. A systematic review and meta-analysis of the efficacy and safety of intermittent preventive treatment of malaria in children (IPTc). PLoS One. 2011;6(2):e16976.

142. Cairns M, Roca-Feltrer A, Garske T, Wilson AL, Diallo D, Milligan PJ, et al. Estimating the potential public health impact of seasonal malaria chemoprevention in African children. Nat Commun. 2012;3:881.

143.• van Eijk AM, Larsen DA, Kayentao K, Koshy G, DEC S, Roper C, et al. Effect of Plasmodium falciparum sulfadoxinepyrimethamine resistance on the effectiveness of intermittent preventive therapy for malaria in pregnancy in Africa: a systematic review and meta-analysis. Lancet Infect Dis. 2019;19(5):546-56 This meta-analysis of 57 studies including $\mathbf{5 9 , 4 5 7}$ births describes the effects of SP resistance on the protective effects of intermittent preventive therapy in pregnancy. Overall, IPTpSP was associated with reduced low birthweight in areas with $>90 \%$ of quintuple mutant dhps $540 \mathrm{E}$ parasites, but was not protective in areas with $>10 \%$ prevalence of highly resistant dhps $581 \mathrm{G}$ parasites.

144.• Esu EB, Oringanje C, Meremikwu MM. Intermittent preventive treatment for malaria in infants. Cochrane Database Syst Rev. 2019;12:CD011525 Meta-analysis of 12 trials of IPTi effectiveness in moderate- to high-transmission areas of sub-Saharan Africa. Trials included SP, AQ, DHA-PPQ, AS-AQ, and ASSP. The authors noted waning efficacy of SP observed over a 19-year period, believed to reflect the increasing prevalence of antifolate resistance on the continent.

145. Nayebare P, Asua V, Conrad MD, Kajubi R, Kakuru A, Nankabirwa JI, et al. Associations between malaria preventive regimens and Plasmodium falciparum drug resistance mediating polymorphisms in Ugandan pregnant women. Antimicrob Agents Chemother. 2020; This study compared the frequencies of drug resistance markers in pfmdrl and pfcrt before and during IPTp with DHA-PPQ and found a significant increase in the frequency of $\mathrm{N86Y}$, Y184F, and K76T mutants during IPTp compared to baseline, signaling a potential low barrier to resistance of DHA-PPQ and warning against its propensity for selecting drug-resistant parasites when used in IPT and similar strategies.

146. Conrad MD, Mota D, Foster M, Tukwasibwe S, Legac J, Tumwebaze P, et al. Impact of intermittent preventive treatment during pregnancy on Plasmodium falciparum drug resistancemediating polymorphisms in Uganda. J Infect Dis. 2017;216(8): $1008-17$

147. Jagannathan P, Kakuru A, Okiring J, Muhindo MK, Natureeba P, Nakalembe M, et al. Dihydroartemisinin-piperaquine for intermittent preventive treatment of malaria during pregnancy and risk of malaria in early childhood: a randomized controlled trial. PLoS Med. 2018;15(7):e1002606 A randomized trial of IPTp with either DHA-PPQ or SP in Uganda (2014-2017) examining the primary outcome of $P$. falciparum malaria risk during infancy. To the authors' surprise, malaria incidence in children born to mothers who received IPTp with DHA-PPQ was not reduced, and was in fact observed to be higher in girls than boys, compared to the control arm.

148. Kakuru A, Jagannathan P, Kajubi R, Ochieng T, Ochokoru H, Nakalembe M, et al. Impact of intermittent preventive treatment of malaria in pregnancy with dihydroartemisinin-piperaquine versus sulfadoxine-pyrimethamine on the incidence of malaria in infancy: a randomized controlled trial. BMC Med. 2020;18(1): 207 A similar trial conducted by the same group above at a different site in Uganda (2016-2018) showed reduced infant malaria in boys only in the DHA-PPQ group compared to the IPTp-SP control group.

149. Moore BR, Benjamin JM, Tobe R, Ome-Kaius M, Yadi G, Kasian $\mathrm{B}$, et al. A randomized open-label evaluation of the antimalarial prophylactic efficacy of azithromycin-piperaquine versus sulfadoxine-pyrimethamine in pregnant Papua New Guinean women. Antimicrob Agents Chemother. 2019;63(10).

150. Zongo I, Milligan P, Compaore YD, Some AF, Greenwood B, Tarning J, et al. Randomized noninferiority trial of dihydroartemisinin-piperaquine compared with sulfadoxinepyrimethamine plus amodiaquine for seasonal malaria chemoprevention in Burkina Faso. Antimicrob Agents Chemother. 2015;59(8):4387-96.

151. Kimani J, Phiri K, Kamiza S, Duparc S, Ayoub A, Rojo R, et al. Efficacy and safety of azithromycin-chloroquine versus sulfadoxine-pyrimethamine for intermittent preventive treatment of Plasmodium falciparum malaria infection in pregnant women in Africa: an open-label, randomized trial. PLoS One. 2016;11(6): e0157045.

152. Gonzalez R, Desai M, Macete E, Ouma P, Kakolwa MA, Abdulla $\mathrm{S}$, et al. Intermittent preventive treatment of malaria in pregnancy with mefloquine in HIV-infected women receiving cotrimoxazole prophylaxis: a multicenter randomized placebo-controlled trial. PLoS Med. 2014;11(9):e1001735.

153. Newby G, Hwang J, Koita K, Chen I, Greenwood B, von Seidlein $\mathrm{L}$, et al. Review of mass drug administration for malaria and its operational challenges. Am J Trop Med Hyg. 2015;93(1):125-34.

154. World Health Organization. The role of mass drug administration, mass screening and treatment, and focal screening and treatment for malaria. Geneva, Switzerland: WHO Global Malaria Programme; 2015.

155. Spangenberg T, Burrows JN, Kowalczyk P, McDonald S, Wells TN, Willis P. The open access malaria box: a drug discovery catalyst for neglected diseases. PLoS One. 2013;8(6):e62906.

156.• Delves MJ, Miguel-Blanco C, Matthews H, Molina I, Ruecker A, Yahiya S, et al. A high throughput screen for next-generation leads targeting malaria parasite transmission. Nat Commun. 2018;9(1): 3805 Report of high-throughput screening of $>\mathbf{6 8 , 0 0 0}$ compounds from the Global Health Chemical Diversity Library against male and female $P$. falciparum gametocytes that identified 17 potential lead compounds.

157. Nwaka S. Drug discovery and beyond: the role of public-private partnerships in improving access to new malaria medicines. Trans R Soc Trop Med Hyg. 2005;99(Suppl 1):S20-9.

158.• Zhang M, Wang C, Otto TD, Oberstaller J, Liao X, Adapa SR, et al. Uncovering the essential genes of the human malaria parasite Plasmodium falciparum by saturation mutagenesis. Science. 2018;360(6388) Using transposon mutagenesis in $\boldsymbol{P}$. falciparum, the authors generated $>38,000$ mutants encompassing 5399 among which 2680 genes were identified as essential for in vitro growth of asexual blood stages, representing potential drug and vaccine targets as well as capturing 1000 Plasmodium-conserved genes of currently unknown function.

159. Bushell E, Gomes AR, Sanderson T, Anar B, Girling G, Herd C, et al. Functional profiling of a Plasmodium genome reveals an abundance of essential genes. Cell. 2017;170(2):260-72 e8.

160. Okour M, Derimanov G, Barnett R, Fernandez E, Ferrer S, Gresham S, et al. A human microdose study of the antimalarial drug GSK3191607 in healthy volunteers. Br J Clin Pharmacol. 2018;84(3):482-9.

161. Bakshi RP, Nenortas E, Tripathi AK, Sullivan DJ, Shapiro TA. Model system to define pharmacokinetic requirements for antimalarial drug efficacy. Sci Transl Med. 2013;5(205).

162. Wallender E, Zhang N, Conrad M, Kakuru A, Muhindo M, Tumwebaze $\mathrm{P}$, et al. Modeling prevention of malaria and selection of drug resistance with different dosing schedules of dihydroartemisinin-piperaquine preventive therapy during pregnancy in Uganda. Antimicrob Agents Chemother. 2019;63(2). 
163. Intharabut B, Kingston HW, Srinamon K, Ashley EA, Imwong M, Dhorda M, et al. Artemisinin resistance and stage dependency of parasite clearance in falciparum malaria. J Infect Dis. 2019;219(9): 1483-9.

164. Khoury DS, Zaloumis SG, Grigg MJ, Haque A, Davenport MP. Interdisciplinary approaches to malaria C. malaria parasite clearance: what are we really measuring? Trends Parasitol. 2020;36(5): 413-26.

165. White NJ. Assessment of the pharmacodynamic properties of antimalarial drugs in vivo. Antimicrob Agents Chemother. 1997;41(7):1413-22.

166. Sinxadi P, Donini C, Johnstone H, Langdon G, Wiesner L, Allen E, et al. Safety, tolerability, pharmacokinetics, and antimalarial activity of the novel Plasmodium phosphatidylinositol 4-kinase inhibitor MMV390048 in healthy volunteers. Antimicrob Agents Chemother. 2020;64(4).

167. Valecha N, Looareesuwan S, Martensson A, Abdulla SM, Krudsood S, Tangpukdee N, et al. Arterolane, a new synthetic trioxolane for treatment of uncomplicated Plasmodium falciparum malaria: a phase II, multicenter, randomized, dosefinding clinical trial. Clin Infect Dis. 2010;51(6):684-91.

168. McCarthy JS, Lotharius J, Ruckle T, Chalon S, Phillips MA, Elliott S, et al. Safety, tolerability, pharmacokinetics, and activity of the novel long-acting antimalarial DSM265: a two-part first-inhuman phase $1 \mathrm{a} / 1 \mathrm{~b}$ randomised study. Lancet Infect Dis. 2017;17(6):626-35.

169.• Llanos-Cuentas A, MVG L, Hien TT, Velez ID, Namaik-Larp C, $\mathrm{Chu} \mathrm{CS}$, et al. Tafenoquine versus primaquine to prevent relapse of Plasmodium vivax malaria. N Engl J Med. 2019;380(3):229-41 Randomized trial of tafenoquine compared to primaquine for preventing relapse of $P$. vivax malaria across 7 study sites in South America and Southeast Asia. There was no difference in the proportion of participants who were infection-free at 6 months (67 vs $73 \%)$, and the trial failed to establish noninferiority of tafenoquine compared to primaquine. Nevertheless, the authors rightfully highlight the operational advantages of the long-acting alternative to primaquine.

170. Kisalu NK, Idris AH, Weidle C, Flores-Garcia Y, Flynn BJ, Sack $\mathrm{BK}$, et al. A human monoclonal antibody prevents malaria infection by targeting a new site of vulnerability on the parasite. Nat Med. 2018;24(4):408-16.

171. Gaur AH, McCarthy JS, Panetta JC, Dallas RH, Woodford J, Tang L, et al. Safety, tolerability, pharmacokinetics, and antimalarial efficacy of a novel Plasmodium falciparum ATP4 inhibitor SJ733: a first-in-human and induced blood-stage malaria phase 1a/b trial. Lancet Infect Dis. 2020;20(8):964-75.

172. Brunschwig C, Lawrence N, Taylor D, Abay E, Njoroge M, Basarab GS, et al. UCT943, a next-generation Plasmodium falciparum PI4K inhibitor preclinical candidate for the treatment of malaria. Antimicrob Agents Chemother. 2018;62(9).

173. Dalmat R, Naughton B, Kwan-Gett TS, Slyker J, Stuckey EM. Use cases for genetic epidemiology in malaria elimination. Malar J. 2019;18(1):163.

174. Rao PN, Uplekar S, Kayal S, Mallick PK, Bandyopadhyay N, Kale S, et al. A method for amplicon deep sequencing of drug resistance genes in Plasmodium falciparum clinical isolates from India. J Clin Microbiol. 2016;54(6):1500-11.

175. L'Episcopia M, Kelley J, Patel D, Schmedes S, Ravishankar S, Menegon M, et al. Targeted deep amplicon sequencing of kelch 13 and cytochrome b in Plasmodium falciparum isolates from an endemic African country using the Malaria Resistance Surveillance (MaRS) protocol. Parasit Vectors. 2020;13(1):137.

176. Talundzic E, Ravishankar S, Kelley J, Patel D, Plucinski M, Schmedes $\mathrm{S}$, et al. Next-generation sequencing and bioinformatics protocol for malaria drug resistance marker surveillance. Antimicrob Agents Chemother. 2018;62(4).
177. Nag S, Dalgaard MD, Kofoed PE, Ursing J, Crespo M, Andersen LO, et al. High throughput resistance profiling of Plasmodium falciparum infections based on custom dual indexing and Illumina next generation sequencing-technology. Sci Rep. 2017;7(1):2398

178. Levitt B, Obala A, Langdon S, Corcoran D, O'Meara WP, Taylor SM. Overlap extension barcoding for the next generation sequencing and genotyping of Plasmodium falciparum in individual patients in Western Kenya. Sci Rep. 2017;7:41108.

179. Juliano JJ, Porter K, Mwapasa V, Sem R, Rogers WO, Ariey F, et al. Exposing malaria in-host diversity and estimating population diversity by capture-recapture using massively parallel pyrosequencing. Proc Natl Acad Sci U S A. 2010;107(46):20138-43.

180. Taylor SM, Parobek CM, Aragam N, Ngasala BE, Martensson A, Meshnick SR, et al. Pooled deep sequencing of Plasmodium falciparum isolates: an efficient and scalable tool to quantify prevailing malaria drug-resistance genotypes. J Infect Dis. 2013;208(12):1998-2006.

181. Brazeau NF, Assefa A, Mohammed H, Seme H, Tsadik AG, Parr $\mathrm{JB}$, et al. Pooled deep sequencing of drug resistance loci from Plasmodium falciparum parasites across Ethiopia. Am J Trop Med Hyg. 2019;101(5):1139-43.

182. Boyce RM, Brazeau N, Fulton T, Hathaway N, Matte M, Ntaro M, et al. Prevalence of molecular markers of antimalarial drug resistance across altitudinal transmission zones in highland Western Uganda. Am J Trop Med Hyg. 2019;101(4):799-802.

183. Hathaway NJ, Parobek CM, Juliano JJ, Bailey JA. SeekDeep: single-base resolution de novo clustering for amplicon deep sequencing. Nucleic Acids Res. 2018;46(4):e21.

184. Lerch A, Koepfli C, Hofmann NE, Messerli C, Wilcox S, Kattenberg JH, et al. Development of amplicon deep sequencing markers and data analysis pipeline for genotyping multi-clonal malaria infections. BMC Genomics. 2017;18(1):864.

185. Early AM, Daniels RF, Farrell TM, Grimsby J, Volkman SK, Wirth DF, et al. Detection of low-density Plasmodium falciparum infections using amplicon deep sequencing. Malar J. 2019;18(1): 219.

186. Ishengoma DS, Saidi Q, Sibley CH, Roper C, Alifrangis M. Deployment and utilization of next-generation sequencing of Plasmodium falciparum to guide anti-malarial drug policy decisions in sub-Saharan Africa: opportunities and challenges. Malar J. 2019;18(1):267.

187. Volkman SK, Herman J, Lukens AK, Hartl DL. Genome-wide association studies of drug-resistance determinants. Trends Parasitol. 2017;33(3):214-30.

188. Agrawal S, Moser KA, Morton L, Cummings MP, Parihar A, Dwivedi A, et al. Association of a novel mutation in the Plasmodium falciparum chloroquine resistance transporter with decreased piperaquine sensitivity. J Infect Dis. 2017;216(4):46876.

189. Amaratunga K, Tarasuk J, Tsegaye L, Archibald CP. Communicable, Infectious Disease Steering C, et al. Advancing surveillance of antimicrobial resistance: summary of the 2015 CIDSC Report. Can Commun Dis Rep. 2016;42(11):232-7.

190. Cheeseman IH, Miller BA, Nair S, Nkhoma S, Tan A, Tan JC, et al. A major genome region underlying artemisinin resistance in malaria. Science. 2012;336(6077):79-82.

191. Mu J, Myers RA, Jiang H, Liu S, Ricklefs S, Waisberg M, et al. Plasmodium falciparum genome-wide scans for positive selection, recombination hot spots and resistance to antimalarial drugs. Nat Genet. 2010;42(3):268-71.

192. Takala-Harrison S, Clark TG, Jacob CG, Cummings MP, Miotto O, Dondorp AM, et al. Genetic loci associated with delayed clearance of Plasmodium falciparum following artemisinin treatment in Southeast Asia. Proc Natl Acad Sci U S A. 2013;110(1):240-5. 
193. Takala-Harrison S, Jacob CG, Arze C, Cummings MP, Silva JC, Dondorp AM, et al. Independent emergence of artemisinin resistance mutations among Plasmodium falciparum in Southeast Asia. J Infect Dis. 2015;211(5):670-9.

194. Van Tyne D, Park DJ, Schaffner SF, Neafsey DE, Angelino E, Cortese JF, et al. Identification and functional validation of the novel antimalarial resistance locus PF10 0355 in Plasmodium falciparum. PLoS Genet. 2011;7(4):e10013̄83.

195. Amato R, Lim P, Miotto O, Amaratunga C, Dek D, Pearson RD, et al. Genetic markers associated with dihydroartemisininpiperaquine failure in Plasmodium falciparum malaria in Cambodia: a genotype-phenotype association study. Lancet Infect Dis. 2017;17(2):164-73.

196. Henden L, Lee S, Mueller I, Barry A, Bahlo M. Identity-bydescent analyses for measuring population dynamics and selection in recombining pathogens. PLoS Genet. 2018;14(5):e1007279.

197. Nair S, Nash D, Sudimack D, Jaidee A, Barends M, Uhlemann AC, et al. Recurrent gene amplification and soft selective sweeps during evolution of multidrug resistance in malaria parasites. Mol Biol Evol. 2007;24(2):562-73.

198. Schaffner SF, Taylor AR, Wong W, Wirth DF, Neafsey DE. hmmIBD: software to infer pairwise identity by descent between haploid genotypes. Malar J. 2018;17(1):196.

199. Taylor AR, Jacob PE, Neafsey DE, Buckee CO. Estimating relatedness between malaria parasites. Genetics. 2019;212(4):133751.

200. Taylor AR, Schaffner SF, Cerqueira GC, Nkhoma SC, Anderson TJC, Sriprawat K, et al. Quantifying connectivity between local Plasmodium falciparum malaria parasite populations using identity by descent. PLoS Genet. 2017;13(10):e1007065.

201. Wilson BA, Garud NR, Feder AF, Assaf ZJ, Pennings PS. The population genetics of drug resistance evolution in natural populations of viral, bacterial and eukaryotic pathogens. Mol Ecol. 2016;25(1):42-66.

202. Roper C, Pearce R, Nair S, Sharp B, Nosten F, Anderson T. Intercontinental spread of pyrimethamine-resistant malaria. Science. 2004;305(5687):1124.

203. Amato R, Pearson RD, Almagro-Garcia J, Amaratunga C, Lim P, Suon S, et al. Origins of the current outbreak of multidrug-resistant malaria in southeast Asia: a retrospective genetic study. Lancet Infect Dis. 2018;18(3):337-45.

204. Hassett MR, Roepe PD. Origin and spread of evolving artemisinin-resistant Plasmodium falciparum malarial parasites in Southeast Asia. Am J Trop Med Hyg. 2019;101(6):1204-11.

205. Imwong M, Suwannasin K, Kunasol C, Sutawong K, Mayxay M, Rekol H, et al. The spread of artemisinin-resistant Plasmodium falciparum in the Greater Mekong subregion: a molecular epidemiology observational study. Lancet Infect Dis. 2017;17(5):4917.

206. Li Y, Shetty AC, Lon C, Spring M, Saunders DL, Fukuda MM, et al. Detecting geospatial patterns of Plasmodium falciparum parasite migration in Cambodia using optimized estimated effective migration surfaces. Int J Health Geogr. 2020;19(1):13.

207. Shetty AC, Jacob CG, Huang F, Li Y, Agrawal S, Saunders DL, et al. Genomic structure and diversity of Plasmodium falciparum in Southeast Asia reveal recent parasite migration patterns. Nat Commun. 2019;10(1):2665 Molecular epidemiologic study of $P$. falciparum migration within Southeast Asia using identityby-descent approaches that demonstrated discrete parasite populations and migration patterns showing potential utility in tracking and containing parasite drug resistance.

208. Zhu SJ, Almagro-Garcia J, McVean G. Deconvolution of multiple infections in Plasmodium falciparum from high throughput sequencing data. Bioinformatics. 2018;34(1):9-15.

209. Zhu SJ, Hendry JA, Almagro-Garcia J, Pearson RD, Amato R, Miles A, et al. The origins and relatedness structure of mixed infections vary with local prevalence of $\mathrm{P}$. falciparum malaria. Elife. 2019;8.

210. Morgan AP, Brazeau NF, Ngasala B, Mhamilawa LE, Denton M, Msellem M, et al. Falciparum malaria from coastal Tanzania and Zanzibar remains highly connected despite effective control efforts on the archipelago. Malar J. 2020;19(1):47.

211.• Verity R, Aydemir O, Brazeau NF, Watson OJ, Hathaway NJ, Mwandagalirwa MK, et al. The impact of antimalarial resistance on the genetic structure of Plasmodium falciparum in the DRC. Nat Commun. 2020;11(1):2107 This study used molecular inversion probes to sequence $2537 P$. falciparum infections from the Democratic Republic of the Congo between 2013 and 2015 to study population structure and drug resistance. They identified an East-West spatial distribution of drug-resistant haplotypes for chloroquine and sulfadoxine-pyrimethamine and showed that selection for these drug-resistant haplotypes contributed to population structure within the country. This novel approach demonstrates the potential for high-throughput genomics to study changes in antimalarial resistance.

212. Deutsch-Feldman M, Aydemir O, Carrel M, Brazeau NF, Bhatt S, Bailey JA, et al. The changing landscape of Plasmodium falciparum drug resistance in the Democratic Republic of Congo. BMC Infect Dis. 2019;19(1):872.

213.• Cowell AN, Istvan ES, Lukens AK, Gomez-Lorenzo MG, Vanaerschot M, Sakata-Kato T, et al. Mapping the malaria parasite druggable genome by using in vitro evolution and chemogenomics. Science. 2018;359(6372):191-9 Drug resistance genomics (resistome) study of $\boldsymbol{P}$. falciparum describing novel drug target-inhibitor pairs, informing drug discovery efforts while confirming resistance markers and adding to our understanding of resistance mechanisms.

214. Cowell AN, Winzeler EA. Advances in omics-based methods to identify novel targets for malaria and other parasitic protozoan infections. Genome Med. 2019;11(1):63.

215. Demas AR, Sharma AI, Wong W, Early AM, Redmond S, Bopp $\mathrm{S}$, et al. Mutations in Plasmodium falciparum actin-binding protein coronin confer reduced artemisinin susceptibility. Proc Natl Acad Sci U S A. 2018;115(50):12799-804.

216. Henrici RC, Edwards RL, Zoltner M, van Schalkwyk DA, Hart MN, Mohring F, et al. The Plasmodium falciparum artemisinin susceptibility-associated AP-2 adaptin mu subunit is clathrin independent and essential for schizont maturation. mBio. 2020;11(1).

217. Henrici RC, van Schalkwyk DA, Sutherland CJ. Modification of pfap2mu and pfubp1 Markedly reduces ring-stage susceptibility of Plasmodium falciparum to artemisinin in vitro. Antimicrob Agents Chemother. 2019;64(1).

218. Hawkes M, Conroy AL, Opoka RO, Namasopo S, Zhong K, Liles $\mathrm{WC}$, et al. Slow clearance of Plasmodium falciparum in severe pediatric malaria, Uganda, 2011-2013. Emerg Infect Dis. 2015;21(7):1237-9.

219. Ghorbal M, Gorman M, Macpherson CR, Martins RM, Scherf A, Lopez-Rubio JJ. Genome editing in the human malaria parasite Plasmodium falciparum using the CRISPR-Cas9 system. Nat Biotechnol. 2014;32(8):819-21.

220. Lee MC, Fidock DA. CRISPR-mediated genome editing of Plasmodium falciparum malaria parasites. Genome Med. 2014;6(8):63.

221. Ng CL, Fidock DA. Plasmodium falciparum in vitro drug resistance selections and gene editing. Methods Mol Biol. 2019;2013: 123-40 This chapter discusses the most current methods used to generate antimalarial-resistant $\boldsymbol{P}$. falciparum strains in vitro. Genetic editing methods such as zinc-finger nucleases and CRISPR/Cas9 have made studying the effects of specific genetic changes more accessible where before they were often prohibitively laborious or even impossible. Parasite lines 
generated using these methods have greatly contributed to our understanding of antimalarial resistance.

222. Singer M, Marshall J, Heiss K, Mair GR, Grimm D, Mueller AK, et al. Zinc finger nuclease-based double-strand breaks attenuate malaria parasites and reveal rare microhomology-mediated end joining. Genome Biol. 2015;16:249.

223. Straimer J, Lee MC, Lee AH, Zeitler B, Williams AE, Pearl JR, et al. Site-specific genome editing in Plasmodium falciparum using engineered zinc-finger nucleases. Nat Methods. 2012;9(10):993-8.

224. Wagner JC, Platt RJ, Goldfless SJ, Zhang F, Niles JC. Efficient CRISPR-Cas9-mediated genome editing in Plasmodium falciparum. Nat Methods. 2014;11(9):915-8.

225. Straimer J, Gnadig NF, Witkowski B, Amaratunga C, Duru V, Ramadani AP, et al. Drug resistance K13-propeller mutations confer artemisinin resistance in Plasmodium falciparum clinical isolates. Science. 2015;347(6220):428-31.

226. Dhingra SK, Gabryszewski SJ, Small-Saunders JL, Yeo T, Henrich PP, Mok S, et al. Global spread of mutant PfCRT and its pleiotropic impact on Plasmodium falciparum multidrug resistance and fitness. mBio. 2019;10(2).

227. Dhingra SK, Redhi D, Combrinck JM, Yeo T, Okombo J, Henrich $\mathrm{PP}$, et al. A Variant PfCRT isoform can contribute to Plasmodium falciparum resistance to the first-line partner drug piperaquine. mBio. 2017;8(3).

228. Ng CL, Siciliano G, Lee MC, de Almeida MJ, Corey VC, Bopp SE, et al. CRISPR-Cas9-modified pfmdr1 protects Plasmodium falciparum asexual blood stages and gametocytes against a class of piperazine-containing compounds but potentiates artemisininbased combination therapy partner drugs. Mol Microbiol. 2016;101(3):381-93.

229. Pelleau S, Moss EL, Dhingra SK, Volney B, Casteras J, Gabryszewski SJ, et al. Adaptive evolution of malaria parasites in French Guiana: reversal of chloroquine resistance by acquisition of a mutation in pfcrt. Proc Natl Acad Sci U S A. 2015;112(37):11672-7.

230.• Ross LS, Dhingra SK, Mok S, Yeo T, Wicht KJ, Kumpornsin K, et al. Emerging Southeast Asian PfCRT mutations confer Plasmodium falciparum resistance to the first-line antimalarial piperaquine. Nat Commun. 2018;9(1):3314 Between 2010 and
2014, widespread DHA-PPQ treatment failure occurred in Cambodia. This study demonstrates how the emergence of pfcrt variants that confer high-level resistance to piperaquine on an artemisinin-resistant parasite background contributed to this failure. This manuscript is an excellent example of how molecular epidemiology, in vitro gene editing, pharmacological assays, and cell biology can be synthesized to gain insight into antimalarial resistance.

231. Straimer J, Gnadig NF, Stokes BH, Ehrenberger M, Crane AA, Fidock DA. Plasmodium falciparum K13 mutations differentially impact ozonide susceptibility and parasite fitness in vitro. mBio. 2017;8(2).

232. Moraes Barros RR, Straimer J, Sa JM, Salzman RE, MelendezMuniz VA, Mu J, et al. Editing the Plasmodium vivax genome, using zinc-finger nucleases. J Infect Dis. 2015;211(1):125-9.

233. Kirkman LA, Deitsch KW. Recombination and diversification of the variant antigen encoding genes in the malaria parasite Plasmodium falciparum. Microbiol Spectr. 2014;2(6).

234. Kirkman LA, Lawrence EA, Deitsch KW. Malaria parasites utilize both homologous recombination and alternative end joining pathways to maintain genome integrity. Nucleic Acids Res. 2014;42(1):370-9.

235. Gardner MJ, Hall N, Fung E, White O, Berriman M, Hyman RW, et al. Genome sequence of the human malaria parasite Plasmodium falciparum. Nature. 2002;419(6906):498-511.

236. Xiao B, Yin S, Hu Y, Sun M, Wei J, Huang Z, et al. Epigenetic editing by CRISPR/dCas9 in Plasmodium falciparum. Proc Natl Acad Sci U S A. 2019;116(1):255-60 Innovation of CRISPR/ Cas9 applications in $\boldsymbol{P}$. falciparum using an epigenetic knockdown system. The authors used this approach to characterize essential parasite genes.

237. Shinzawa N, Nishi T, Hiyoshi F, Motooka D, Yuda M, Iwanaga S. Improvement of CRISPR/Cas9 system by transfecting Cas9expressing Plasmodium berghei with linear donor template. Commun Biol. 2020;3(1):426.

Publisher's Note Springer Nature remains neutral with regard to jurisdictional claims in published maps and institutional affiliations. 